NBER WORKING PAPER SERIES

\title{
BEHAVIORAL RESPONSES TO SUPPLY-SIDE DRUG POLICY DURING THE OPIOID EPIDEMIC
}

\author{
Simone Balestra \\ Helge Liebert \\ Nicole Maestas \\ Tisamarie B. Sherry \\ Working Paper 29596 \\ http://www.nber.org/papers/w29596 \\ NATIONAL BUREAU OF ECONOMIC RESEARCH \\ 1050 Massachusetts Avenue \\ Cambridge, MA 02138 \\ December 2021
}

We are grateful to Abby Alpert, Josh Angrist, Michael Barnett, Stefan Boes, Colleen Carey, Caroline Chuard, Dhaval Dave, Beatrix Eugster, Ellen Meara, Owen O'Donnell, Rosalie Pacula, David Powell, Fanny Puljic, Sara Rellstab, Aurelien Sallin, Lukas Schmid, Molly Schnell, Hannes Schwandt, and Romain Wacziarg for their constructive comments. The paper benefited from the valuable feedback of participants in the following meetings: NBER Improving Health Outcomes for an Aging Population, American Society of Health Economists, Royal Economic Society, Swiss Society of Economics and Statistics, Swiss Society of Health Economics, and departmental seminars at Harvard, Lucerne, Rotterdam, St. Gallen, and Zurich. We thank Blue Cross Blue Shield Association and the Blue Cross Blue Shield Alliance for Health Research for data access and supportive advice. We thank Laurie Meneades and Joel Frischknecht for excellent research programming support. Balestra and Liebert acknowledge funding from the Richard Buchner Foundation, which we thank for their support. Liebert acknowledges funding from the Swiss National Science Foundation, grant no. 184377. Maestas and Sherry gratefully acknowledge funding from the National Institute on Aging (P01AG005842) and a gift from Owen and Linda Robinson. Maestas has served as an expert witness in litigation involving opioids. Harvard Medical School participates in the Blue Cross Blue Shield Alliance for Health Research. This study was conceived and drafted when Sherry was was employed at the RAND Corporation, and the findings and views in this manuscript do not necessarily reflect the official views or policy of her current employer, the U.S. Department of Health and Human Services, nor the U.S. Government. The views expressed herein are those of the authors and do not necessarily reflect the views of the National Bureau of Economic Research.

NBER working papers are circulated for discussion and comment purposes. They have not been peer-reviewed or been subject to the review by the NBER Board of Directors that accompanies official NBER publications.

(C) 2021 by Simone Balestra, Helge Liebert, Nicole Maestas, and Tisamarie B. Sherry. All rights reserved. Short sections of text, not to exceed two paragraphs, may be quoted without explicit permission provided that full credit, including (C) notice, is given to the source. 
Behavioral Responses to Supply-Side Drug Policy During the Opioid Epidemic

Simone Balestra, Helge Liebert, Nicole Maestas, and Tisamarie B. Sherry

NBER Working Paper No. 29596

December 2021

JEL No. I12,I18

\section{ABSTRACT}

We investigate behavioral responses to a staggered disruption in the supply of prescription opioids across U.S. states: the introduction of electronic Prescription Drug Monitoring Programs (PDMPs). Using administrative datasets, we find PDMPs curtail the proliferation of prescription opioids. Physicians respond to monitoring on the extensive margin, limiting the number of patients to whom they prescribe opioids without adjusting dosage or duration. This decreases supply to long-term opioid users, who evade the restrictions by acquiring prescriptions from out-of-state prescribers and by substituting to heroin. This causes a surge in heroin overdoses, which offsets reductions in hospitalizations and deaths from prescription opioids.

Simone Balestra

University of St. Gallen

Varnbüelstrasse 14

9000 St. Gallen

Switzerland

simone.balestra@unisg.ch

Helge Liebert

Department of Economics

University of Zurich

Schönberggasse 1

Zurich 8001

Switzerland

helge.liebert@econ.uzh.ch
Nicole Maestas

Department of Health Care Policy

Harvard Medical School

180 Longwood Avenue

Boston, MA 02115

and NBER

maestas@hcp.med.harvard.edu

Tisamarie B. Sherry

RAND Corporation

Arlington, VA

tisa.sherry@gmail.com

A data appendix is available at http://www.nber.org/data-appendix/w29596 


\section{Introduction}

In the last 20 years, use of prescription opioids has grown dramatically in the United States. Since 1999, the number of opioid prescriptions increased by 300\%, surpassing 255 million prescriptions in 2012 (81.3 prescriptions per 100 people) before declining to 153 million prescriptions by 2019 (46.7 per 100 people) (CDC, 2020; U.S. Department of Health \& Human Services, 2016). Opioids may be an effective analgesic for acute pain but are also associated with high risks of addiction and overdose (Fields, 2011). Death rates from opioid poisoning tripled between 2000 and 2014 (Rudd et al., 2016), contributing to a stunning reversal in the long-running decline in midlife mortality since 1999 (Case and Deaton, 2015). The increase in overdose deaths was initially driven by prescription opioid poisonings, but the more recent surge in deaths has been attributed to illicit opioids such as heroin and fentanyl (Rudd et al., 2016).

In efforts to abate the opioid epidemic, federal, state and local governments have implemented an array of policies aimed at curbing harms related to prescription opioid misuse. These policies typically follow one of three lines of attack: prevention of opioid misuse, treatment of opioid use disorder (OUD), and reducing drug availability (Office of National Drug Control Policy, 2020). While prevention and treatment are demand-side interventions, reducing drug availability targets the opioid supply. Throughout the epidemic, policymakers have relied heavily on supply-side interventions. Half of all federal drug control funding ( $\$ 17$ billion) for fiscal year 2020 was assigned to supply reduction, 44 percent was allocated to treatment ( $\$ 15$ billion) and only six percent to prevention ( $\$ 2$ billion). ${ }^{1}$ Although supplyside interventions dominate drug policy, evidence of their effectiveness is mixed (e.g., Alpert, Powell, and Pacula, 2018; Buchmueller and Carey, 2018; Dobkin and Nicosia, 2009; Evans, Lieber, and Power, 2019; Haegerich et al., 2014; Mauri, Townsend, and Haffajee, 2020).

At the state level, Prescription Drug Monitoring Programs (PDMPs) are the primary tool used to control the supply of prescription opioids. ${ }^{2}$ PDMPs record patients' prescription histories, with the purpose of facilitating detection of suspicious fill patterns, "doctor shopping," or other behaviors indicative of prescription drug misuse. By raising awareness among physicians of the risks of opioid prescribing, and facilitating detection of inappropriate prescribing, PDMPs are intended to discourage excess or high-risk opioid prescribing, thereby limiting exposure of consumers to opioids and preventing addiction. But,

\footnotetext{
${ }^{1}$ In the last decade, the budget allocated to supply reduction has been stable at \$15-17 billion per year, while that allocated to demand reduction has been steadily increasing from $\$ 9$ billion in 2011 to $\$ 17$ billion in 2020 (Office of National Drug Control Policy, 2019).

${ }^{2}$ Other common supply-side interventions (both state and federal) include Medicaid "lock-ins" that limit patients to a single, designated opioid prescriber, the development of abuse-deterrent drug formulations, "black box" warnings on drug packaging, regulations targeting pain clinics, and limits on the duration and potency of initial prescriptions.
} 
in creating access barriers, PDMPs may inadvertently increase the likelihood that individuals who are already addicted to prescription opioids switch to illicit opioids - primarily heroin and fentanyl traded on the black market. This is known as the "balloon effect" (Mora, 1996): when the government closes down a source of drug supply, individuals dependent on these substances resort to other sources instead of reducing drug use. Indeed, deaths from heroin and synthetic opioids have surged to record numbers nationwide, increasing seven-fold since 2012 and now surpassing deaths from firearms and car crashes combined (CDC, 2021).

In this paper, we conduct a comprehensive investigation of the direct and indirect effects of PDMPs. Our research design leverages the staggered implementation of electronic PDMPs across U.S. states between 1993-2018. We have assembled a comprehensive suite of large administrative and survey data not used in previous studies to examine the effects of prescription drug regulation across a broad range of outcomes and actors, revealing the chain of events that unfolds after an opioid supply disruption limits access to prescription drugs.

We first test whether PDMPs are effective at limiting the proliferation of prescription opioids. Using the nation's largest database of commercial insurance claims, Blue Cross Blue Shield (BCBS) Axis ${ }^{\circledR}$, we find that electronic PDMPs reduce the overall number of opioid prescriptions by $14 \%$ and the number of people receiving opioid analgesics by $13 \%$. We corroborate this finding in data from the Drug Enforcement Administration (DEA), which track shipments of oxycodone and hydrocodone (the two most commonly prescribed opioid analgesics) from manufacturers to dispensers. These data confirm that PDMPs reduce the volume of dispensing by both pharmacies and practitioners.

We then focus on the behavioral responses of prescribers across a heterogeneous set of patients. Our analysis reveals that providers respond entirely on the extensive margin; reducing the number of prescriptions they issue but not their daily dosage or duration. While physicians limit opioid prescriptions across a diverse set of patients, first-time prescriptions to opioid-naive patients are reduced the most. However, the majority of the reduction arises from limiting prescriptions to long-term opioid users - a smaller set of users that nevertheless accounts for the majority of prescription volume. This extensive margin response cuts off patients with a history of chronic opioid use - and therefore a higher risk of opioid dependence - from a steady supply of legal prescription drugs.

Patients respond by seeking other sources of opioids. Using BCBS Axis ${ }^{\circledR}$ and the National Survey on Drug Use and Health, we document an increase in the number of prescriptions obtained from out-ofstate prescribers. At the same time, patients are also more likely to rely on diverted prescription drugs or other illicit drugs, primarily heroin. The number of individuals who report using heroin increases by 
9\%. We then compute bounds for the rate of substitution between prescription opioids and heroin. Our preferred estimate suggests that for every six prescription drug users who lose legal access to opioids after PDMP introduction, one person initiates heroin consumption.

Probing further, we investigate whether these PDMP-induced reductions in prescribing translate into health improvements. Our results suggest that aggregate mortality estimates hide meaningful and opposing health effects arising from changes in the consumption patterns of people dependent on opioids. Although mortality due to semi-synthetic prescription opioids decreases, aggregate mortality remains unaffected by PDMPs. This is because mortality due to heroin and fully synthetic opioids (e.g., fentanyl) increases sharply, by about $14 \%$, reflecting the substitution towards illicit drugs. Our results suggest that although prescription drug mortality is reduced permanently, heroin mortality spikes sharply following the introduction of a PDMP and remains at an elevated level.

Having established the existence and magnitude of substitution effects for mortality, we focus on hospitalizations as a non-terminal health outcome and assess the costs imposed on the health care system. Using the National Inpatient Sample, we find that hospitalizations due to prescription opioid poisoning decrease, while those caused by heroin poisoning increase. As in the case of mortality, overall opioid hospitalizations remain stable. Although average effects are similar to those for mortality, the time pattern of hospitalization effects differs. In the years following PDMP introduction, hospitalizations for both prescription opioid and heroin poisonings steadily decrease and increase, respectively. This suggests that as heroin consumption spreads, harm reduction practices become more established and the risk of fatal overdose decreases while hospitalization becomes more likely.

These changes in the composition of hospital cases are costly: total hospital costs associated with opioid poisonings increase by $3 \%$. Most of the additional costs are borne by commercial insurers and not by Medicaid or Medicare. Excess hospitalizations occur mostly among middle-aged, white and commercially insured individuals. While both men and women are affected, incidence among men is higher compared to women. In the final part of the paper, we present a case study of pain clinics in Florida ("pill mills"), where providers engaged in excessive prescribing practices, to highlight their unique role in sustaining widespread opioid addiction.

Our paper contributes novel findings to four distinct strands of literature. First, we advance the growing literature on prescription monitoring. This literature has largely focused on elderly and disabled Medicare beneficiaries (e.g., Buchmueller and Carey, 2018; Meara et al., 2016), even though evidence suggests middle-aged, commercially insured individuals have been most affected by the opioid epidemic (see Case and Deaton, 2015; Ruhm, 2019). Understanding outcomes for the general population is of 
widespread interest. Krueger (2017) argued that the proliferation of prescription opioids could account for up to $43 \%$ of the decline in men's labor force participation between 1999 and 2015 . We show that a large part of the policy incidence falls on commercial insurance enrollees, while broadly confirming previous results for Medicare beneficiaries (Buchmueller and Carey, 2018).

Most studies in this literature investigate effects on opioid prescriptions and misuse outcomes (e.g., Brady et al., 2014; Buchmueller and Carey, 2018; Grecu, Dave, and Saffer, 2019; Mauri, Townsend, and Haffajee, 2020; Meara et al., 2016; Simoni-Wastila and Qian, 2012). Among studies of the most restrictive type of electronic PDMP, which requires physicians and pharmacies to check patients' prescription records prior to dispensing, there is consensus that "must-access" laws cause moderate reductions in prescriptions and opioid misuse. But studies of PDMPs more broadly or of their effects on other outcomes present mixed results. For example, the few studies focusing on mortality offer conflicting results: Pardo (2017) finds that PDMPs are associated with a reduction in opioid overdoses, whereas Grecu, Dave, and Saffer (2019) and Meinhofer (2018) do not find any relation between PDMPs and mortality. Results for other health outcomes, which could help resolve these conflicting findings are scarce. ${ }^{3}$ Our analysis incorporates the full class of electronic PDMPs and looks beyond prescriptions patterns to a broad array of health outcomes, health care use and costs in the general population, adding to the limited evidence on mortality.

In addition, few studies have assessed downstream outcomes, such as heroin use. ${ }^{4}$ Individuals who lose access to opioids may turn to illicit markets to obtain substitute drugs in the form of diverted prescription opioids, heroin, or fentanyl. Theoretical work by Strulik (2021) suggests out that discontinuing a prescription induces fully rational individuals to quit using opioids, while imperfectly rational individuals experiencing addiction switch to heroin. We advance the literature by quantifying these indirect effects, tracing how PDMPs affect drug consumption, hospitalizations, and mortality associated with illicit opioids.

Our paper also informs the broader literature on supply-side drug policies by illustrating how consumers react to supply contractions. Limited effectiveness and evasion of supply-side restrictions have been documented for a wide range of drugs. For example, Dobkin and Nicosia (2009) analyze the effects

\footnotetext{
${ }^{3}$ Another potential explanation for the divergent findings in the literature is the heterogeneity of the particular PDMP legislation under study and related measurement error (Griffin et al., 2020; Horwitz et al., 2018; Schuler et al., 2020, see also). Buchmueller and Carey (2018) focus on must-access PDMP laws. They find that must-access PDMPs reduce excessive quantity prescriptions and doctor shopping behavior in the Medicare Part D prescription drug program. Grecu, Dave, and Saffer (2019) add that must-access PDMPs decrease treatment admissions for substance abuse and reduce opioid mortality for younger adults, while Kim (2021) show that the introduction of must-access PDMPs caused an increase in heroin mortality.

${ }^{4}$ Notable exceptions are Grecu, Dave, and Saffer (2019), who study treatment admissions for drug misuse, Gihleb, Giuntella, and Zhang (2019), who study the effect of must-access PDMPs on foster care admissions, and Evans, Harris, and Kessler (2020), who examine how child abuse and neglect change after must-access PDMP implementation and OxyContin reformulation.
} 
of supply disruptions in the market for methamphetamine across a range of outcomes, and find that the impact is largely temporary. ${ }^{5}$ Closely related to our paper, Cicero and Ellis (2015), Alpert, Powell, and Pacula (2018) and Evans, Lieber, and Power (2019) analyze the 2010 abuse-deterrent reformulation of OxyContin and its effects on drug consumption. They find that while the reformulation has reduced illicit use of OxyContin, it has also caused individuals to switch to other opioid drugs, primarily heroin. Building on this evidence, we show that evasion and drug substitution also occur on a large scale in response to prescription monitoring. We pin down the physician and consumer behaviors that drive this result and link these behaviors to health outcomes and health care costs. Our analysis highlights the gatekeeper role and special responsibility of physicians in prescription drug markets. ${ }^{6}$

Lastly, our paper informs the recent discourse about the causes of the opioid epidemic and the interpretation of recent trends in mortality. Case and Deaton (2015) documented the reversal in mortality trends in the United States, pointing out the historic increase in rates of mortality by drug poisoning among middle-aged, white non-Hispanics compared to other demographic groups, and also a pronounced increase in suicides and deaths from chronic liver disease and cirrhosis. They tie these "deaths of despair" to economic insecurity, interpreting the changes in mortality in the context of a broader deterioration in economic conditions for people without a college degree (Case and Deaton, 2020). Others have explored alternative explanations, arguing that supply-side factors related to public health and the availability of drugs are the major driving forces of the aggregate trend in mortality (e.g., Ruhm, 2016, 2018). These demand and supply-side explanations are complementary and not mutually exclusive (see also Case and Deaton 2017, 2018, 2020; Currie and Schwandt 2020; Meara and Skinner 2015). Grossmann and Strulik (2021) emphasize that both socio-economic decline and falling opioid prices need to coincide to explain the rise in illicit drug use. Institutions also matter: in a recent paper on the origins of the opioid crisis, Alpert et al. (2019) highlight how initial differences in state laws governing the ease with which prescriptions for controlled substances could be issued led to targeted marketing efforts by pharmaceutical companies, which influenced the proliferation of OxyContin. We complement these papers by showing how institutions shape prescribing behavior and access to prescriptions; and how prescribing laws can induce drug substitution in the presence of illicit substitutes.

\footnotetext{
${ }^{5}$ Evaluations of supply-side drug policy interventions are available for methamphetamine (Dobkin and Nicosia, 2009; Dobkin, Nicosia, and Weinberg, 2014), cocaine (Caulkins, 2001), heroin (Smithson, McFadden, and Mwesigye, 2005), and marijuana (DiNardo and Lemieux, 2001). For a general discussion on drug policy, see Murphy, Grossman, and Becker (2006).

${ }^{6}$ For a broader discussion on the key role of physician behavior during the opioid epidemic, see Schnell (2017) and Schnell and Currie (2018).
} 


\section{Background}

Opioids are a class of natural and synthetic substances that act by binding to opioid receptors, which are found principally in the central and peripheral nervous system and the gastrointestinal tract. These receptors mediate both the psychoactive and the somatic effects of opioids, relieving pain and creating a feeling of relaxation and sometimes euphoria. However, because of their effect on the part of the brain that regulates breathing, opioids can lead to respiratory depression during overdoses.

Beginning in the mid-1990s, the medical community began treating pain more aggressively, easing access to prescription painkillers. Following this paradigm shift, opioid prescribing increased significantly over the next two decades. Previously, opioids had been utilized almost exclusively for the treatment of severe acute pain, pain due to cancer or in palliative care, or were administered in hospital settings and rarely prescribed as self-administered medication. In the mid-1990s, however, physicians began prescribing opioids for people experiencing chronic pain or episodes of minor acute pain, which were previously treated with non-steroidal anti-inflammatory drugs. Today, opioid analgesics - in particular, oxycodone or hydrocodone - are commonly prescribed for conditions like back pain or following dental treatments. The increase in opioid prescriptions has been accompanied by rising rates of opioid misuse, addiction, and overdoses.

In response to growing misuse of prescription medication, U.S. states have introduced prescription drug monitoring programs (PDMPs). A PDMP is an electronic database that tracks prescriptions of controlled substances in a state. The goal of PDMPs is to support the legitimate medical use of controlled substances while limiting their misuse and diversion. Pharmacies and prescribers register with their state PDMP and pharmacies report prescriptions and dispensations of controlled substances to the electronic online database. By providing prescribers and health authorities with information about patient and provider behaviors, they may enable rapid identification of high-risk prescribing or fill patterns indicating potential misuse (e.g., overlapping prescriptions, multiple prescribers, etc.), thereby facilitating targeted enforcement. PDMPs are thus designed to help prevent adverse drug-related events such as opioid overdoses, drug diversion, and substance misuse by decreasing unsafe or potentially inappropriate opioid prescribing. As of 2020, 49 states have active PDMPs that track patients' prescription histories of controlled substances.

The primary goal of PDMPs is to limit access to opioid medication to legitimate users only. This type of supply-side restriction is similar in spirit to other drug policies like abuse-deterrent drug formulations, lock-in programs used in Medicaid, or box warnings. From an economic perspective, theory predicts 
that policies which reduce the supply of a specific drug should lead to an increase in the price of the drug, in turn lowering its quantity demanded (e.g., Reuter and Kleiman, 1986). However, with health insurance as the primary payer, this price mechanism only holds for diverted opioids on the secondary market. Moreover, substitution responses by consumers may partially undo the benefits of these policies. By increasing the cost of prescription opioid misuse, the introduction of a PDMP likely decreases consumption of opioid medication, but could induce a proportion of existing consumers to substitute toward illicit opioids like heroin, fentanyl, or other related substances.

The health risks associated with these black market opioids are large: they are more potent, more addictive, typically cheaper than prescription painkillers, are often used with non-sterile injecting equipment that can lead to infectious complications, and may vary in their concentration or in the presence of dangerous contaminants that together can substantially increase the risk of overdose. In contrast, prescription opioids are of known strength and purity and free from contaminants or adulterants. Overdose risks have also increased tremendously with the increased availability of fentanyl and the established practice of cutting heroin with cheaper fentanyl. Fentanyl is about 100 times as potent as morphine (from which heroin is derived). Due to its higher potency, fentanyl is easier to smuggle across borders and has become progressively more popular on illicit drug markets. Compared to heroin, which is typically manufactured from morphine obtained from poppy seeds, fentanyl can be synthesized from precursor chemicals with relative ease. However, since illicit drug suppliers do not have access to the same technology as professional labs, the concentration of fentanyl can vary substantially, and improper mixing techniques by drug suppliers leave "hot-spots" of fentanyl in the final product that are often lethal, especially for intravenous drug users.

The secondary goal of PDMPs is to limit potential supplier-induced demand for prescription opioids and to curb the pill mill phenomenon. Physicians can use the PDMP to query patients' treatment histories. Prescription information is automatically registered when prescriptions are dispensed. The automatic record taking and easy access to these records can potentially affect prescriber behavior. PDMPs can typically also be accessed by law enforcement, which can use the database to identify and prosecute physicians or clinics that prescribe opioids freely to patients with minimal checks. There is widespread anecdotal evidence that PDMPs lead to the closure of pill mill-type pain clinics. With a PDMP, prescribers are more likely to face professional consequences for excessive prescribing. Hence, they may be reluctant to start new patients on opioids (turning to non-opioid pain medication instead), more likely to decrease the duration/potency among current opioid patients, or perhaps both. It is a priori unclear which behavioral response will prevail. We answer this question empirically by examining prescrip- 
tions at the extensive margin (new prescriptions) and intensive margin (potency and duration of existing prescriptions).

PDMP legislation and programs exhibit some degree of heterogeneity. In this paper, we examine electronic PDMPs. Electronic PDMPs are now the most common type of program (see Horwitz et al., 2018) and consist of real-time, easy-to-access query systems. We discard PDMPs that were introduced early as a registration system when real-time queries were still technically impossible (for example, the first PDMP in New York dates back to 1972). Within the class of electronic PDMPs, some states adopted "mandated" or "must-access" PDMPs, which legally require prescribers to query them under certain circumstances. We refrain from looking exclusively at must-access PDMPs, as these are only introduced in a small number of states, mostly during a limited time period (2011-2013), directly following the abuse-deterrent reformulation of OxyContin in August 2010 (Evans, Lieber, and Power, 2019). Since we have assembled a comprehensive range of data not used in previous studies, we choose to examine the effects of electronic PDMPs more generally and over a longer time period.

\section{Data}

For the present study, we combine information on states' laws and regulations from multiple sources, prescription claims from Blue Cross Blue Shield Axis ${ }^{\circledR}$, drug shipment records from the DEA's Automation of Reports and Consolidated Orders System, drug consumption data from the National Survey on Drug Use and Health, street prices for prescription drugs from StreetRx, individual-level mortality data from the Centers for Disease Control and Prevention, and case-level hospitalization data from the National Inpatient Sample. Appendix Table A.1 gives a complete overview of all the state-level variables.

\subsection{PDMP Implementation Data}

The focus of the present paper is to examine the effect of modern (electronic) PDMPs. Modern PDMPs are electronic systems that provide direct web-based access to prescribers and dispensers. We count a program as operational if the end user (e.g., physician, pharmacist, or member of law enforcement) can query a database directly, rather than through a phone call or fax because the latter are unlikely to allow the user to access patient histories. This is a major difference from the literature, which either uses legislated start dates for any PDMP or is unspecific about their protocol in choosing a definition of a PDMP and the relative enactment date (for a general discussion on this topic, see Horwitz et al., 2018).

Our primary source of information about state laws is the detailed database collected by the Pre- 
scription Drug Abuse Policy System (PDAPS). This database was created by trained legal researchers who independently reviewed - and are perpetually reviewing - state laws on PDMP operations. The database contains information about each state's PDMP regulation, the exact contents of the law and dates of enactment or modification (Davis, Pierce, and Dasgupta, 2014). We utilize the PDAPS data as a starting point and complement it with records from the states' statutes, the National Alliance for Model State Drug Laws (NAMSDL), and the Prescription Drug Monitoring Program Training and Technical Assistance Center (TTAC).

While identifying which PDMPs are electronic is relatively easy, determining exactly when these PDMPs became operational is more challenging. Complications arise because reported dates often differ and original sources for databases like PDAPS or NAMSDL are sometimes missing. ${ }^{7}$ For the few cases where we were not able to find a reliable source for the operational date, we rely on the dates provided by Horwitz et al. (2018), who apply a research protocol similar to ours for electronic PDMPs. Our final PDMP database is consistent with the dates identified by Schuler et al. (2020) in the RAND PDMP policy data and Horwitz et al. (2018), who started working on PDMP operational dates around the same times as we did. Appendix Table A.2 provides a comprehensive overview of each state's PDMP, from legislative enactment (column 1) to active operational status of a modern electronic PDMP (column 2).

Appendix Figure A.1 illustrates the staggered introduction of PDMPs by plotting the cumulative number of operational PDMPs over time. At the beginning of our observation period, no state has an electronic PDMP, whereas towards the end of our time frame nearly all states have one. In contrast to most previous studies, we focus on a longer time frame, both before and after the introduction of a PDMP. This allows us to better assess the internal validity of the identification strategy and, at the same time, examine potential delayed and longer-term effects.

\subsection{Blue Cross Blue Shield Axis ${ }^{\circledR}$ Claims Data}

To analyze prescription use patterns, we access data from Blue Cross Blue Shield (BCBS) Association. Blue Cross Blue Shield affiliated insurers offer health insurance plans in all U.S. states. Together, the BCBS Association and its licensees are the largest commercial insurance group in the U.S., and the BCBS Axis ${ }^{\circledR}$ database is the largest source of commercial insurance claims. The BCBS Axis ${ }^{\circledR}$ data represent prescribing by three-quarters of active, non-federal physicians. In 2018, more than 106 million people - one in three Americans - were covered by BCBS health insurance plans.

Our sample consists of 210,051,436 observations of unique commercial enrollee-plan combina-

\footnotetext{
${ }^{7}$ Moreover, some states also operated pilot programs, but we take the date at which the full program became operational.
} 
tions between 2012 to 2018 and a total of 133,042,732 opioid prescription claims. ${ }^{8}$ Over this time period, BCBS records a total of 109.7 billion Morphine Milligram Equivalent (MME) units dispensed by providers, amounting to over 520 milligrams per enrollee-plan combination. ${ }^{9}$

Our data are based on the full sample of members without imposing further restrictions. To account for the fact that BCBS insurance coverage varies by state, we control for the lagged number of enrollees in all empirical models. Based on the individual claims data, we construct measures of the total number of opioid prescriptions, the total number of long-duration or high-dose prescriptions, and the total MME amount prescribed for each state per year. In the claims data, the prescription duration is recorded as number of days' supply. We compute prescription strength as the MME-per-day dose based on the recorded drug strength per dose unit, the number of units per day and the drug-specific MME conversion factor. To measure the average strength of an opioid prescription and to disentangle extensive and intensive margin effects of PDMPs on prescriber behavior, we also calculate the total number of days supplied and the average MME amount/day per claim.

For acute pain, the Centers for Disease Control and Prevention (CDC) recommends prescribers start patients on the lowest effective dose of opioids, and opioid prescriptions above 50 MME per day should be carefully considered (CDC, 2016; Dowell, Haegerich, and Chou, 2016). Prescriptions above 50 $\mathrm{MME} /$ day are associated with a twofold increased overdose risk compared to a lower dose sufficient for pain relief. Prescriptions should only be issued for the expected duration of pain severe enough to require opioids, and rarely for longer than seven days. Following the CDC's guidelines, we define problematic prescriptions as either long-duration (days' supply $\geq 7$ ) or high-dose (daily MME amount $\geq 50$ $\mathrm{mg})$.

To examine prescriber behavior in more detail, we distinguish between prescriptions to chronic opioid users and initial prescriptions to opioid-naive patients. We define chronicity as at least 90 days of consecutive use following established practice (e.g., Brummett et al., 2017; Martin et al., 2011). Since consecutive prescriptions are difficult to disentangle in the claims, we identify chronic use as receiving at least a 90 days' supply in a given year. To further identify chronic long-term users, we also consider higher durations (at least 180/360 days' supply) and additional potency thresholds. Following Zhu et al. (2019), we define opioid-naive patients as enrollees without any history of opioid prescribing in the last six months. Again, we differentiate between high-dose and long-duration prescriptions to examine prescriber responses in detail.

\footnotetext{
${ }^{8}$ Enrollees are identified through a member ID. If an individual changes insurance plan, he or she will receive a new member ID.

${ }^{9}$ This estimate is lower than corresponding per-individual estimates based on ARCOS data as we only observe unique individual-plan combinations, and consider a younger, commercially-enrolled population.
} 
Figure 1: Average MME Amount Prescribed per BCBS Enrollee-Plan Combination Across the United States in 2012

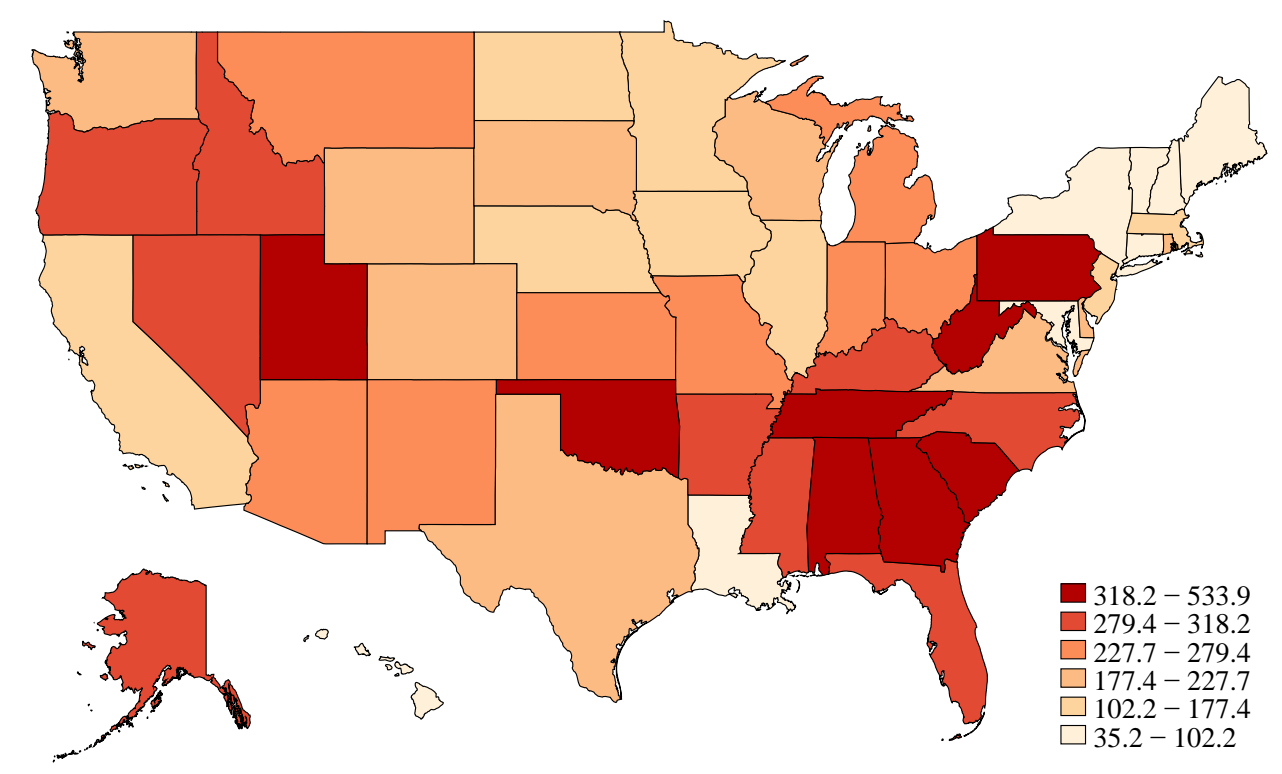

Note: The map plots the average total MME amount per enrolled member-plan combination of all opioid prescriptions in the Blue Cross Blue Shield claims data for 2012. The categories are based on sextiles of the MME amount per member. Data are from the Blue Cross Blue Shield Axis ${ }^{\circledR}$ database.

To investigate patient responses to the supply restrictions, we also develop measures of doctor shopping. Similar to Rose et al. (2018), we define doctor shopping as individuals who receive prescriptions from at least three different prescribers within a 3-month window. To examine whether consumers attempt to evade detection by the PDMP in response to the policy, we differentiate between in-state and out-of-state doctor shopping. Out-of-state doctor shopping occurs when individuals who engage in doctor shopping acquire one or more of their prescriptions from out-of-state prescribers.

We find that in 2018, 21\% of all opioid prescriptions exceeded the CDC's recommendation for initial prescriptions of 50 MME per day. These high-strength prescriptions are not restricted to a small number of chronic-use individuals: Across the U.S., $21 \%$ of enrollees who received an opioid prescription received a prescription strength above $50 \mathrm{MME}$ at least once, and $20 \%$ of initial prescriptions to opioidnaive patients exceeded the $50 \mathrm{MME}$ limit. The problem of excessive opioid prescribing is widespread across the United States: In 33 states, more than one in five prescriptions exceeded the CDC's guideline, and in no state was the rate lower than one in ten. Figure 1 shows that prescription strength, while excessive in some states, is universally high across the U.S.

Patterns of opioid usage are highly skewed. We find that about $1 \%$ of enrollees are chronic opioid users. These users account for a disproportionate share of opioid consumption. Consistently, about 50\% of all opioid prescriptions are filled by chronic users, and they account for $85 \%$ of the total MME-amount consumed. 


\subsection{DEA Automation of Reports and Consolidated Orders System}

To further investigate the effectiveness of PDMPs in reducing opioid misuse and prescriptions, we utilize data from the DEA's Automation of Reports and Consolidated Orders System (ARCOS). ARCOS is a drug reporting system which monitors shipments of controlled substances from the manufacturer to the dispenser - retailers, practitioners and hospitals. Under federal law, manufacturers and distributors must report all transactions of controlled substances to the DEA. The ARCOS database tracks these transactions. The database was partially published by the Washington Post after a protective order was lifted following legal action. The database is available from 2006 and 2014 and covers nearly 500 million transactions. We focus on shipments of two of the most prominent opioid medications, oxycodone and hydrocodone, and distinguish between shipments to pharmacies and to practitioners.

\subsection{National Survey on Drug Use and Health}

To investigate drug consumption and user behavior, we utilize data from the National Survey on Drug Use and Health (NSDUH), conducted by the Substance Abuse and Mental Health Services Administration (SAMHSA). The NSDUH is a nationally representative, biannual household survey and the largest source of information on drug use patterns and user health available in the United States. The survey is available in two-year waves from 2002-2003 to 2017-2018, with a structural break in some questions in 2014. The data contain detailed information on the use of pain medication, heroin and other drugs. Respondents are asked whether they ever used a specific drug. This facilitates analysis of incidence, since changes in the rate of "ever use" come about only from first-time use. The outcomes we focus on are the overall use of pain relievers, non-medical use of pain relievers ("not directed by a doctor"), overall and non-medical use of sedatives or tranquilizers, and use of heroin and benzodiazepines specifically. Benzodiazepines are frequently misused and one of the most common drugs associated with polysubstance use of opioids (Jones, Mogali, and Comer, 2012; Sun et al., 2017). We also investigate whether respondents received treatment for substance misuse at a facility. For the substance use outcomes, we are focusing on first-time use ('ever used'), because data on past-year use is not consistently available for all outcomes over the analysis time frame. This implies that we are picking up effects on incidence (new users initiating drug use) rather than prevalence.

Regrettably, access to the restricted individual-level NSDUH data is currently not possible. We obtain the state-level data from the online data portal, which restricts access to variables that have low case counts in some states. The NSDUH data is representative of persons aged 12 and over in the civilian noninstitutionalized population in each state. State estimates are obtained using a survey-weighted hi- 
erarchical Bayes methodology. We only rely on data for which a balanced state-year panel is available. This prevents us from studying outcomes for other specific substances, drug dependence and treatment admissions in more detail. ${ }^{10}$

Since the NSDUH relies on self-reported information on drug use, underreporting of drug use is a potential issue. The NSDUH assures survey participants of a confidential environment and safety from criminal prosecution. A small-sample validation study by Harrell (1997) shows that reporting of illicit drug use was accurate in 68-96\% of cases, depending on drug type. As noted by Alpert, Powell, and Pacula (2018) who also use the NSDUH data, unless underreporting is systematically related to state geography, it will not confound the treatment effect estimates.

\subsection{StreetRx: Street prices for Illicit and Prescription Drugs}

We obtain data on street prices for prescription drugs using crowd-sourced data from streetrx.com. StreetRx is a review site that aggregates prices and ratings for illicit street purchases of prescription drugs. Users enter the specific drug they purchased, where they bought it and how much they paid for it. The site also lists the prices for a specific substance and dosage paid within the last two weeks so users can get a reference price for their area. We exclude all prices associated with bulk purchases from the data. We then measure both the number of purchases registered, the prices paid, and the price per mg for commonly prescribed opioids. Since PDMPs potentially affect both the demand for opioids and the supply of legal prescription opioids diverted to black markets, we use the StreetRx data to investigate whether PDMPs ultimately affect the equilibrium prices paid for opioids on the street.

\subsection{National Vital Statistics System Individual Mortality Data}

Mortality data are made available by the CDC through the National Vital Statistics System (NVSS). Death certificates are coded by the states and provided to the National Center for Health Statistics, the data center of the CDC. Each death certificate records the main cause of death, additional contributing causes, and demographic information. Causes of death are coded according to the ninth revision of the World Health Organization's (WHO) International Classification of Diseases (ICD-9) until 1998 and according to the tenth revision since 1999 (ICD-10). This transition complicates our analysis because,

\footnotetext{
${ }^{10}$ Access to the individual-level has been restricted by SAMHSA. A new, restricted-use data portal was under construction since 2016 and became available in 2019. The new portal provides aggregated location-specific information, but requests for many variables are prohibited due to a limited number of respondents in some data cells. SAMHSA migrated the restricted-use microdata to the National Center for Health Statistics for use at their Federal Statistical Research Data Centers. The NSDUH microdata was unavailable for our study, both due to the ongoing migration and the subsequent access restriction due to the COVID-19 pandemic. Other researchers have been facing the same issue with the NSDUH data and use the limited available state-level information in lieu of alternatives (Alpert, Powell, and Pacula, 2018).
} 
while we can disentangle the cause of death by opioid type in the ICD-10 data, this is not possible with the ICD-9 version. For this reason, we analyze opioid-related mortality in aggregate for the 1993-2017 period while we examine mortality by opioid type from 1999 onward.

Identifying opioid deaths with ICD-9 classification is straightforward, because only two dedicated categories exist: "opiates and related narcotics" for poisonings and "opioid type dependence" for drug misuse. Our focus in this paper is primarily on poisonings, which refer to overdose deaths. To identify opioid-related deaths in the ICD-10 data, we proceed as follows. First, we select the underlying cause of death, which in our case is drug induced (ICD-10 X40-44, X60-64, X85, Y10-14). ${ }^{11}$ Second, among deaths with drug overdose as the underlying cause, the type of opioid is indicated by the following ICD10 multiple cause-of-death codes: opium (T40.0), heroin (T40.1), natural and semi-synthetic opioids (T40.2), methadone (T40.3), synthetic opioids other than methadone (T40.4), other and unspecified narcotics (T40.6). In addition to mortality related to opioid poisonings, we also analyze mortality associated with opioid dependence syndrome caused by repeated substance use (F11.2).

The disambiguation by drug category beginning in 1999 allows us to separate mortality due to common prescription opioids and illicit drugs. Popular prescription painkillers like oxycodone (e.g., OxyContin, Percocet), hydrocodone (Vicodin) and hydromorphone (Dilaudid) are all semi-synthetic. Similarly, heroin is listed in its own category. Fentanyl, often illicitly sold as heroin, is the most common fully synthetic opioid. Since different causes of death are not mutually exclusive and some deaths may involve more than one type of drug, our estimates reflect the presence of a drug. Although we cannot attribute mortality to a single cause if multiple drugs are mentioned on the death certificate, the data allow analysis of substitution patterns across different substances.

Since we rely on drug-specific mortality information from the NVSS, it is important that reports for causes of death based on individual death certificates are reliable. Reporting of multiple drugs and causes of death has improved over time (Ruhm, 2016). Concerns about the use of drug-specific mortality data have emerged mostly regarding the reliability of the county-level data (Jones et al., 2019; McClellan, 2019), which we do not use. Although variations in reporting of multiple causes may lead us to understate the effect of supply-side restrictions, it is unlikely that improvements in reporting are directly associated with PDMP introduction.

We aggregate the data at the state level and calculate mortality rates as deaths per 100,000 population. The dependent variables measuring opioid-related mortality are divided in two groups. First, we consider the entire time period (1993-2017) and mix ICD-9 and ICD-10 classifications if, for a given ICD-9 code,

\footnotetext{
${ }^{11}$ For robustness, we also perform the analysis for all-cause mortality, with no tangible impact on the results.
} 
an ICD-10 analogue exists. Second, we consider the shorter - yet more disaggregated by drug type ICD-10 period (1999-2017).

\subsection{National Inpatient Sample}

The National Inpatient Sample (NIS) is a database developed for the Healthcare Cost and Utilization Project (HCUP), which is sponsored by the Agency for Healthcare Research and Quality. The NIS is the largest publicly available all-payer inpatient health care database in the United States, yielding national estimates of hospital inpatient stays. The NIS is the only nationwide hospital database with information on all types of patients, including persons covered by Medicare, Medicaid, private insurance, and the uninsured. This broad inclusion criteria is a major advantage of our study compared to the prior literature, which focuses on Medicare patients (Buchmueller and Carey, 2018), patients admitted in treatment facilities for substance misuse (Grecu, Dave, and Saffer, 2019), or disabled adults in Medicare (Meara et al., 2016), because it increases the external validity of our results.

NIS data are available from 1988 through 2015, and the number of states participating in the NIS has grown from 8 in the first year to 46, plus the District of Columbia, at present. Designed to approximate a $20 \%$ sample of U.S. community hospitals each year, the NIS contains data from more than 7 million hospital stays each year. Although the NIS data are available until 2015, all geographical identifiers have been removed since 2012. We also drop the first five years of data, because the NIS was re-designed and improved in 1993. The only sample restriction we impose on the NIS data is to exclude hospitals that appear in the data only twice or less. In sum, the estimation sample covers the years 1993-2011 and comprises 16,369 hospital-year observations from 2,973 hospitals.

For each sampled hospital, we observe the universe of hospitalizations in a given year. For each patient admitted, we know the admission type (emergency, urgent, or elective), the primary diagnosis, and all medical and surgical procedures administered. Diagnoses and procedures are coded according to the ICD-9-CM classification, which allows disambiguation of hospitalizations by drug class. ${ }^{12}$ The NIS also registers patient characteristics (gender, age, and race), the length of stay (in days), total hospital charges, and the expected primary payer (Medicare, Medicaid, private insurance, self-pay, or other).

Given that the dataset is a hospital panel, the dependent variables are expressed in counts per hospital. For example, for a given hospital we observe how many opioid poisonings occur in a certain year, using information extracted directly from the primary diagnosis. For each poisoning by opiates and re-

\footnotetext{
${ }^{12}$ The International Classification of Diseases, Ninth Revision, Clinical Modification (ICD-9-CM) is the official classification system of diagnoses and procedures associated with hospital utilization in the United States and based on the World Health Organization's ICD-9 system.
} 
lated narcotics, we know the opioid type according to the following categories: opium alkaloids, heroin, methadone, or other. The category "opium alkaloids" includes all derivatives of thebaine, the main alkaloid extracted from Papaver bracteatum (Iranian poppy) and converted industrially into a variety of narcotics, including hydrocodone, hydromorphone, oxycodone, oxymorphone, nalbuphine, naloxone, naltrexone, buprenorphine, and etorphine. In the category "other" we find the following opiates: codeine, meperidine, and morphine. For the analyses, we focus on total opioid poisonings, along with the following three sub-categories: opioid medication, heroin, and all others. While opioid medication includes all prescription opioids used as analgesics, heroin consists exclusively of heroin poisonings. The third category is a residual category, which includes methadone, codeine and other narcotic analgesics.

Our main outcomes are opioid-related hospitalizations, total charges and length of stay, for all admissions and the subset of emergency admissions. For heterogeneity analyses we further stratify by gender and race.

\section{Empirical Strategy}

The principal analysis tests the impact of the introduction of electronic PDMPs on opioid prescriptions, opioid shipments, opioid consumption, opioid-related mortality, and hospitalizations due to opioid poisonings. We specify the following regression model:

$$
y_{i t}=\exp \left(\alpha_{i}+\mu_{t}+\beta \operatorname{PDMP}_{i t}+X_{i t}^{\prime} \gamma+\varepsilon_{i t}\right)
$$

where $y_{i t}$ is the outcome of interest in unit $i$ (state or hospital) in year $t, \alpha_{i}$ are unit fixed effects, $\mu_{t}$ are time fixed effects, and PDMP $i t$ is an indicator of whether a state has an operational electronic PDMP in a given year. In some models, we include a set of time-varying characteristics (state census population, unemployment rate, per-capita real personal income, per capita real GDP, and hospital size). Throughout the analysis, standard errors are clustered at the state (hospital) level (Griffin et al., 2020). We apply randomization inference to obtain valid p-values whenever we observe the full population, because in such cases the remaining uncertainty is design-based and not sampling-based. Because this inferential method relies on nonparametric tests, no assumptions about the distribution of the error terms are needed and the distribution of the test statistic may be unknown (Fisher, 1935; Hess, 2017; Young, 2019).

We choose the exponential specification because of the non-negative nature of the dependent variables and the (potentially) multiplicative structure of the error terms $\left(\alpha_{i}, \mu_{t}\right.$, and $\left.\varepsilon_{i t}\right)$. We estimate equation (1) using the Poisson fixed-effect estimator, which has been shown to perform better than a linear 
model when the dependent variable is non-negative (Santos Silva and Tenreyro, 2006), has many zeros (Santos Silva and Tenreyro, 2011), or has multiplicative unobserved components (Wooldridge, 1999). Note that the Poisson fixed-effect estimator does not require the dependent variable to be an integer and is also consistent in the presence of over-dispersion; no additional distributional assumption is required for consistency (Fally, 2015). The estimator is a quasi-maximum likelihood estimator; i.e., it is consistent if the mean is correctly specified (like OLS) and does not require the error term to be Poissondistributed. Another attractive feature of the Poisson estimator is that, even though non-linear, it features constant relative effects that can be intuitively interpreted as semi-elasticities. Finally, we follow Ciani and Fisher (2019) who suggest using the non-transformed outcome in difference-in-difference models and estimate an exponential model by Poisson Pseudo Maximum Likelihood, which does not require statistical independence of the error term. ${ }^{13}$

The main identifying assumption is that the treated and the control states exhibit parallel time trends in outcomes before the introduction of an electronic PDMP. In the current setting this assumption requires that prescriptions, mortality rates, and hospitalizations in states with a PDMP would have evolved in the same way as the control states in the absence of a PDMP. Although the parallel-trend assumption cannot be tested directly, we perform three validity checks.

First, we examine the evolution of all outcomes under analysis before the introduction of PDMPs. To do so, we regress the lagged outcomes on the adoption of a PDMP. This exercise will reveal any policy endogeneity or diverging trends in the years leading to a PDMP introduction. The results are shown in the Appendix (tables A.3, A.4, A.5, A.6, A.7 and A.8) where we gradually include up to three lagged years for all outcomes under analysis. Out of 91 models estimated, three F-tests on the lags are statistically significant at conventional levels (one at the $10 \%$ level and two at the 5\% level), no more than what is expected by chance. We thus conclude that pre-PDMP trends in outcomes did not cause the introduction of a PDMP.

Second, to further analyze potential violations of the parallel trends assumption, we conduct an event study. Event-study approaches essentially estimate the treatment effect for each year before, during, and after the introduction of an electronic PDMP. While we do not discuss the results from the event-study approach here (this is done extensively in the results section), we find no significant effect of a PDMP before its actual introduction for all outcomes under analysis.

Third, we employ a series of methodological extensions for difference-indifference models with

\footnotetext{
${ }^{13}$ We have tested the sensitivity of the results to the model choice (linear vs. log-linear Poisson), weighting and other modeling parameters (see Griffin et al., 2020) and verified that our results are qualitatively unchanged by variations. Results for all main specifications in the paper using a conventional linear model are reported in Appendix B.
} 
multiple time periods proposed by Callaway and Sant'Anna (2020). These extensions consist of both robustness checks using a doubly-robust estimand for the aggregate treatment effect on the treated and decomposition of the average treatment effect on the treated by group (where groups are defined by the timing of PDMP adoption). Since this third approach is based on a linear model, we log-transform the outcome (or use the inverse hyperbolic sine transformation in the presence of zeros). We defer the full discussion of these extensions to the results section, but preview here that the Callaway and Sant'Anna (2020) approach yields similar results as our main estimation strategy.

To address potential confounding by alternative state policies implemented during our analysis period, we also test the robustness of our main estimates to controlling for other state prescription drug policies (prescription duration limits, pill mill regulations, good samaritan and naloxone access laws) as well as laws governing access to medical and recreational marijuana through dispensaries. Our estimates are unchanged when adding controls for these time-varying state policies.

Overall, the tests indicate that our identification strategy is valid. Note, however, that not finding any anticipation effects or diverging trends before a PDMP becomes operational is not completely surprising. The exact date of first user access to a PDMP is difficult to anticipate, because user access likely depends on many factors (e.g., funding, pilot programs, system architecture) that are hidden from patients and people dependent on opioids, and interact in complex ways that are difficult to predict.

\section{Results}

This section presents our results in three parts. The first part investigates prescriber behavior by focusing on prescriptions and drug shipments to pharmacies. The second part examines patient behavior from doctor shopping to illicit opioid consumption and drug substitution. The third part deals with the health consequences following the introduction of electronic PDMPs. The core of the analysis revolves around mortality and hospital admissions, along with a brief case study of Florida's pills mills and an investigation of the dynamic health effects.

\subsection{Prescriber Responses}

\subsubsection{Prescriptions and Proliferation of Opioids}

In the first step, we investigate whether PDMPs are effective in achieving their desired aim: reducing the proliferation of opioid prescription drugs by changing providers' prescribing behavior. The results are shown in Table 1, panel A. We first look at the number of all opioid prescription claims registered in the 
BCBS data. We find that introducing a PDMP reduces the number of enrollees who receive an opioid prescription by $13.5 \%$. Similarly, the total number of opioid prescriptions (any type) is reduced by about 13.7\%. Next, we look at the number of high-dosage (MME/day $\geq 50$ ) and long-duration (days' supply $\geq 7$ ) opioid prescriptions. These prescriptions are associated with high risks of addiction and overdose. We find that the number of enrollees with high-dosage prescriptions is reduced by about $13.7 \%$, and the number of prescriptions itself by $12.7 \%$. In the last two columns, we look at very high-dosage prescriptions (MME/day $\geq 90$ ) and long-duration prescriptions. These prescriptions are associated with extremely high risks of addiction and overdose, and the CDC recommends increasing the daily dosage above $90 \mathrm{MME} / \mathrm{day}$ only in exceptional cases. Again, we find that the number of enrollees with such high prescriptions is reduced by $12.6 \%$ and the number of prescriptions by $12.4 \%$.

These results differ from those by Buchmueller and Carey (2018), who find no effect of PDMPs on prescriptions. The most likely explanation for this difference in findings is the difference in study population: we analyze claims from non-elderly enrollees in private health insurance plans, whereas Buchmueller and Carey (2018) analyze claims from enrollees in Medicare Part D. Supply-side restrictions may simply have more bite among the non-elderly, possibly because of more elastic demand among the non-elderly, differential provider responses to monitoring, or a mixture of both. 
Table 1: The Effect of Prescription Drug Monitoring Programs on Opioid Prescriptions

(1)

(2)

(3)

(4)

$(5)$

(6)

(A) PRESCRIPTIONS

\begin{tabular}{|c|c|c|c|c|c|}
\hline \multicolumn{2}{|c|}{ All opioid prescriptions } & \multicolumn{2}{|c|}{ High dosage (MME/day $\geq 50$ ) } & \multicolumn{2}{|c|}{ Very high dosage (MME/day $\geq 90)$} \\
\hline Enrollees & Prescriptions & Enrollees & Prescriptions & Enrollees & Prescriptions \\
\hline $\begin{array}{c}-0.135 \\
(0.035)\end{array}$ & $\begin{array}{c}-0.137 \\
(0.032)\end{array}$ & $\begin{array}{c}-0.137 \\
(0.039)\end{array}$ & $\begin{array}{c}-0.127 \\
(0.033)\end{array}$ & $\begin{array}{c}-0.126 \\
(0.043)\end{array}$ & $\begin{array}{c}-0.124 \\
(0.034)\end{array}$ \\
\hline$[0.000]$ & {$[0.000]$} & {$[0.001]$} & {$[0.000]$} & {$[0.004]$} & {$[0.000]$} \\
\hline
\end{tabular}

(B) Dosage

\begin{tabular}{|c|c|c|c|c|c|c|}
\hline & \multicolumn{6}{|c|}{ (B) DosAGE } \\
\hline & \multicolumn{3}{|c|}{ Total amount } & \multicolumn{3}{|c|}{ Per-claim average } \\
\hline & Dosage in MME & Duration in days & Strength in MME/day & Dosage in MME & Duration in days & Strength in MME/day \\
\hline PDMP & $\begin{array}{c}-0.108 \\
(0.057) \\
{[0.058]}\end{array}$ & $\begin{array}{c}-0.128 \\
(0.032) \\
{[0.000]}\end{array}$ & $\begin{array}{c}-0.167 \\
(0.064) \\
{[0.009]}\end{array}$ & $\begin{array}{c}-0.031 \\
(0.064) \\
{[0.628]}\end{array}$ & $\begin{array}{c}0.009 \\
(0.009) \\
{[0.335]}\end{array}$ & $\begin{array}{c}-0.031 \\
(0.044) \\
{[0.491]}\end{array}$ \\
\hline Covariates & Yes & Yes & Yes & Yes & Yes & Yes \\
\hline State FE & Yes & Yes & Yes & Yes & Yes & Yes \\
\hline Time FE & Yes & Yes & Yes & Yes & Yes & Yes \\
\hline States & 51 & 51 & 51 & 51 & 51 & 51 \\
\hline Observations & 306 & 306 & 306 & 306 & 306 & 306 \\
\hline
\end{tabular}

Note: Results from Poisson regression. Standard errors clustered at the state level are shown in parentheses below the coefficients. P-values are shown in square parentheses below the coefficients. Covariates include state census population (on a logarithmic scale), state unemployment rate, state percapita personal income, state per-capita GDP, and lagged number of BCBS enrollees in the state (on a logarithmic scale). Data are from the Blue Cross Blue Shield Axis ${ }^{\circledR}$ database. 
Figure 2: Event Study: Opioid User Rate

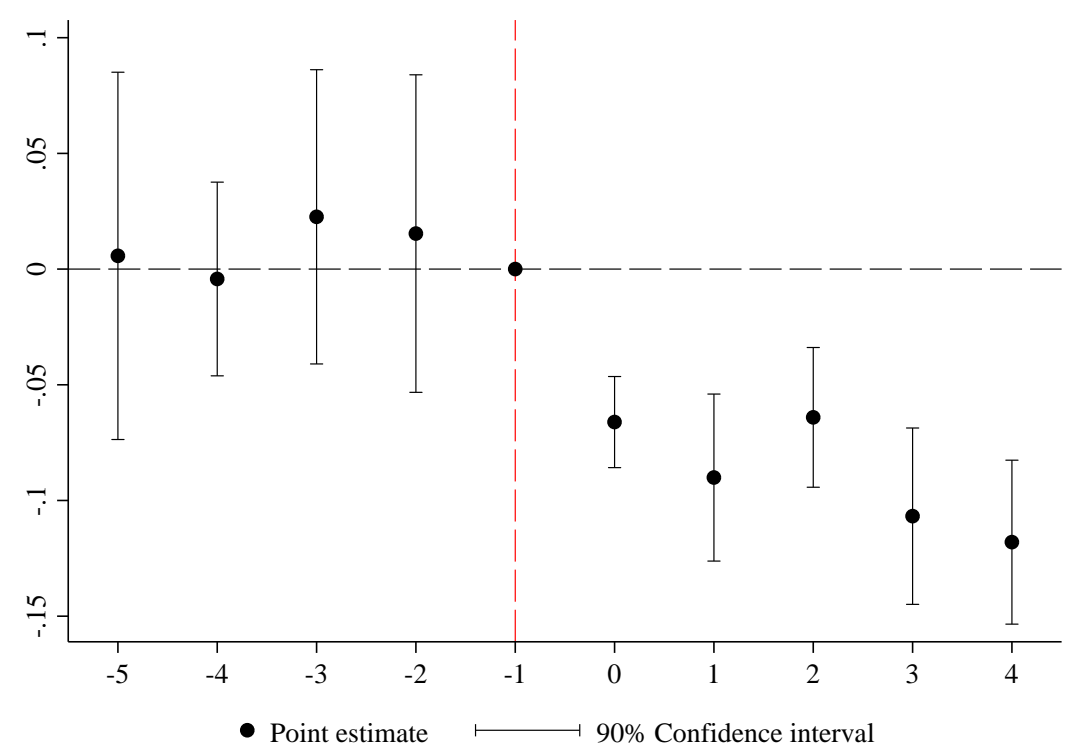

Note: Results from Poisson regression, with standard errors clustered at the state level. Data are from the Blue Cross Blue Shield Axis ${ }^{\circledR}$ database.

Next, we study how prescribers adjust prescriptions by looking at different dosage measures and how they are affected by the introduction of a PDMP (Table 1, panel B). We find a large 10.8\% reduction in the total MME amount prescribed (column 1), and similarly large reductions for total days' supply prescribed and total prescription strength (12.8\% and $16.7 \%$, respectively).

In columns 4-6, we study the MME dosage amount prescribed per claim, the average length of days' supply and the daily MME amount prescribed per claim. These outcomes can be seen as measures of the potency of an individual prescription and allow further insights into how practitioners adjust their prescribing behavior in response to PDMPs. For all three measures, the estimates are indistinguishable from zero. This suggests that practitioners do not adjust the total amount of opioids prescribed, nor the duration of their prescriptions. Together, this implies that practitioners respond only on the extensive margin, reducing the number of prescriptions, but not adjusting the strength of individual prescriptions if they decide to prescribe opioids. This finding is also confirmed by the fact that high-dose/long-duration prescriptions are reduced by about the same relative amount as overall prescriptions. A recent study by (Alpert, Dykstra, and Jacobson, 2020) for Kentucky reports the same type of prescriber response.

We also analyze the change in prescriptions using an event study. In Figure 2, we confirm our finding that prescriptions are permanently lowered following PDMP introduction. The number of opioid users decreases substantially immediately following the operationalizing of a PDMP, and remains permanently lowered. Note that the absence of any pre-trend effects in Figure 2 supports the internal validity of our identification strategy. 
When we distinguish by type of medication (see Appendix Table A.9), we find that reductions are particularly large for oxycodone and hydrocodone. We study these substances in more detail in the next section. In comparison, effects are smaller for medications that are less potent (codeine and tramadol), less commonly prescribed (oxymorphone, morphine, and fentanyl), or for medication treatment of OUD or severe chronic pain only (buprenorphine and methadone). ${ }^{14}$

Before proceeding with the remainder of the results, we discuss alternative estimation methods and the robustness of our results to recent methodological extensions in the difference-in-differences literature (e.g., Callaway and Sant'Anna, 2020; De Chaisemartin and d'Haultfoeuille, 2020; Goodman-Bacon, 2021). We follow the approach by Callaway and Sant'Anna (2020) and separate the analysis in two steps. First, we rely on nonparametric identification of group-time average treatment effects, which we aggregate in the second step to form summary measures of the causal effects. For the first step, we apply the doubly-robust difference-in-differences estimator developed by Sant'Anna and Zhao (2020) and extended to the multiple-period case by Callaway and Sant'Anna (2020). This approach yields a disaggregated causal parameter that is called the group-time average treatment effect, i.e., the average treatment effect for group $g$ at time $t$, where a group is defined by the time period when states introduce their PDMP. In the second step, we aggregate the group-time estimates into an overall average treatment effect on the treated, which we can compare to our main estimates.

Appendix Table A.10 shows the disaggregated effects, replicating the structure of Table 1. States are divided in three groups as follows: early PDMP adopters, intermediate PDMP adopters, and late PDMP adopters. In general, we observe that effects are significant primarily for early and intermediate adopters. In terms of magnitude, the largest effects are found among early adopters. Appendix Table A.11 presents the overall estimate of the group-time effects. We find that the aggregated effects are consistent with both the exponential model (Table 1) and the linear model (Appendix Table B.1). The new estimates are actually slightly larger than our main estimates. In sum, we do not find large differences in the results when using an alternative difference-in-differences estimator. However, for the interpretation of the results, it is important to underscore that primarily early PDMP adopters are driving the effects for prescriptions. As shown in Table A.13, the estimates are also not driven by other state policies.

\footnotetext{
${ }^{14}$ Since methadone for medication treatment is only dispensed through licensed, SAMHSA-certified opioid treatment programs, the prescriptions for methadone we observe in our data are exclusively for non-OUD treatments and most likely issued for chronic pain.
} 
Table 2: The Effect of Prescription Drug Monitoring Programs on Drug Shipments (Oxycodone/Hydrocodone)

\begin{tabular}{|c|c|c|c|c|c|}
\hline & & MANUFAC & URER DRUG ORDER & BY ENTITY & \\
\hline \multirow[b]{2}{*}{ PDMP } & $\begin{array}{c}\text { (1) } \\
\text { Total shipments }\end{array}$ & $\begin{array}{l}\text { (2) } \\
\text { Shipments to } \\
\text { pharmacies }\end{array}$ & $\begin{array}{l}\text { (3) } \\
\text { Shipments to } \\
\text { retail pharmacies }\end{array}$ & $\begin{array}{c}\text { (4) } \\
\text { Shipments to } \\
\text { chain pharmacies }\end{array}$ & $\begin{array}{c}\text { (5) } \\
\text { Shipments to } \\
\text { practitioners }\end{array}$ \\
\hline & $\begin{array}{c}-0.063 \\
(0.026) \\
{[0.000]}\end{array}$ & $\begin{array}{c}-0.057 \\
(0.023) \\
{[0.000]}\end{array}$ & $\begin{array}{l}-0.107 \\
(0.045) \\
{[0.000]}\end{array}$ & $\begin{array}{c}-0.030 \\
(0.015) \\
{[0.000]}\end{array}$ & $\begin{array}{c}-0.804 \\
(0.263) \\
{[0.000]}\end{array}$ \\
\hline Covariates & Yes & Yes & Yes & Yes & Yes \\
\hline State FE & Yes & Yes & Yes & Yes & Yes \\
\hline Time FE & Yes & Yes & Yes & Yes & Yes \\
\hline States & 51 & 51 & 51 & 51 & 51 \\
\hline Observations & 459 & 459 & 459 & 459 & 459 \\
\hline $\begin{array}{l}\text { Note: Results } \mathrm{f} \\
\text { ow the coeffici } \\
1,000 \text { resampli } \\
\text { employment rat } \\
\text { Automation of } \mathrm{I} \\
\text { https ://git }\end{array}$ & $\begin{array}{l}\text { Aoisson regress } \\
\text { s. Randomizatio } \\
\text { replications). C } \\
\text { tate per-capita pe } \\
\text { orts and Consolic } \\
\text {.com/wpinves }\end{array}$ & $\begin{array}{l}\text { n. Standard e } \\
\text { nference p-va } \\
\text { ariates includ } \\
\text { onal income, } \\
\text { es Orders Sys }\end{array}$ & $\begin{array}{l}\text { rs clustered at the } \\
\text { es are shown in sq } \\
\text { tate census popula } \\
\text { d state per-capita } \\
m \text { data, accessed us } \\
\text { - api). }\end{array}$ & $\begin{array}{l}\text { te level are shown } \\
\text { re parentheses belo } \\
\text { n (on a logarithmi } \\
\text { P. Shipments are ba } \\
\text { g the Washington P }\end{array}$ & $\begin{array}{l}\text { parentheses b } \\
\text { the coefficier } \\
\text { scale), state u } \\
\text { ed on the DEA } \\
\text { t's ARCOS A }\end{array}$ \\
\hline
\end{tabular}

\subsubsection{Scheduled Drug Orders and Manufacturer Shipments to Pharmacies}

The results for prescriptions are confirmed when we look at the effect of PDMPs on shipments of scheduled drugs (Table 2). All shipments of scheduled drugs face mandatory registration with the DEA, allowing us to track shipments from manufacturers to pharmacies and practitioners. We find that total shipments of oxycodone and hydrocodone are reduced by $6.3 \%$. Similarly, shipments to pharmacies are reduced by $5.7 \%$. Distinguishing between retail and chain pharmacies, we find that smaller retail pharmacies are more affected by the policy change and reduce their orders to a larger degree. Chain pharmacies, which account for more than $60 \%$ of shipments, are less affected and only reduce their order volume by about $3 \%$. Notably, direct dispensing by practitioners is most affected as shipments to practitioners fall by $80 \%$ following the introduction of a PDMP. However, direct shipments to practitioners only account for about $1 \%$ of all shipments.

The effect size of the reduction in shipments is smaller than that of prescriptions for three reasons. First, the units of measurement are different: while the BCBS data is based on prescriptions, ARCOS measures number of pills. Second, the BCBS claims data covers the full spectrum of opioid medication, while ARCOS considers only two major types of opioid medication (oxycodone and hydrocodone). Third, ARCOS covers the full population, whereas BCBS covers a sub-population of commerciallyinsured individuals. This point is most relevant in light of the generally smaller estimates in the literature for non-commercially insured populations. 


\subsubsection{Prescriptions to Chronic Opioid Users and Opioid-Naive Patients}

Two groups of users are of particular concern from a policy perspective: opioid-naive patients who receive first-time prescriptions, and chronic users who have received high doses of opioids for a longer period. On the one hand, it is important to limit opioid-naive patients' exposure due to the large potential for misuse and harmful side effects of opioids, and prescribe opioids only in cases where their use is clearly indicated and no alternative treatment is available. ${ }^{15}$ On the other hand, chronic users, who may already be suffering from side-effects of long-term opioid use like physical and psychological dependence, risk getting cut off from their supply of medication. The concern is that abrupt discontinuation or reduction in opioid treatment precipitates withdrawal, which is extremely distressing to patients. Indeed, in select populations the risk of overdose or suicide is increased following discontinuation of chronic opioid therapy (Oliva et al., 2020). Rather than ceasing prescribing completely, physicians could start users on opioid dependence treatment or help them taper off.

In Table 3, we study how physicians adjust their prescribing to these two patient groups. In panel A, we estimate the effect of PDMPs on initial use. We assess first-time prescriptions (columns 1-2) and dosage (column 3). Since initial prescriptions are unique, reductions in prescriptions correspond to reductions in users. We find large effects: prescriptions to opioid-naive patients are reduced by about $22.5 \%$. High-dosage prescriptions are reduced even more, by about $25 \%$. We find a similarly large reduction of about $25 \%$ for the dosage amount. This finding mirrors the conclusion of a recent paper by Sacks et al. (2021), who find that must-access PDMPs limit exposure to opioids for new users.

Next, we look at chronic opioid users (panel B). Prescriptions to these patients make up the bulk of all opioids dispensed. Our results indicate that the number of chronic users exceeding 90 days' supply or more is reduced by $12.4 \%$, a magnitude comparable to our main estimate. We then extend the conventional 90-day chronic use definition to specifically estimate effects on long-term users with prescriptions exceeding 180 and 360 days' supply in total. These patients are more likely to have developed opioid dependence. Our results suggest that the reduction in the number of chronic users is stable at about $12 \%-13 \%$. The results for prescriptions (not reported) indicate a similar reduction. When considering dosage (panel C), we again find a similar reduction. The total MME amount dispensed to chronic users falls by about $10 \%$, and up to $13 \%$ when we consider chronic users who have previously received more than a full year's supply of opioids.

To investigate prescribing behavior, we again consider effects on the individual dosage amount. As

\footnotetext{
${ }^{15}$ For this reason, opioids were mostly used in inpatient settings and take-home prescriptions of opioids were limited until the early 1990s. Although opioids are not first-line treatment for chronic pain, chronic opioid treatment can be appropriate in select cases where alternative pain therapies do not achieve an acceptable level of functioning or quality of life.
} 
Table 3: The Effect of Prescription Drug Monitoring Programs on Initial and Long-Duration Opioid Prescriptions

(A) INITIAL OPIOID USERS AND DOSAGE

\begin{tabular}{|c|c|c|c|}
\hline & $\begin{array}{l}\text { (1) } \\
\text { Total enrollees/ } \\
\text { prescriptions }\end{array}$ & $\begin{array}{c}(2) \\
\text { Enrollees with } \\
\mathrm{MME} \geq 50 \mathrm{mg} \text { prescriptions }\end{array}$ & $\begin{array}{c}(3) \\
\text { MME } \\
\text { amount }\end{array}$ \\
\hline PDMP & $\begin{array}{l}-0.225 \\
(0.065) \\
{[0.001]}\end{array}$ & $\begin{array}{l}-0.246 \\
(0.080) \\
{[0.002]}\end{array}$ & $\begin{array}{l}-0.255 \\
(0.087) \\
{[0.003]}\end{array}$ \\
\hline
\end{tabular}

(B) Chronic Opioid USERS

\begin{tabular}{|c|c|c|c|}
\hline & $\begin{array}{l}\text { Enrollees with prescriptions } \\
\text { for more than } 90 \text { days }\end{array}$ & $\begin{array}{l}\text { Enrollees with prescriptions } \\
\text { for more than } 180 \text { days }\end{array}$ & $\begin{array}{l}\text { Enrollees with prescriptions } \\
\text { for more than } 360 \text { days }\end{array}$ \\
\hline PDMP & $\begin{array}{c}-0.124 \\
(0.032) \\
{[0.000]}\end{array}$ & $\begin{array}{c}-0.118 \\
(0.031) \\
{[0.000]}\end{array}$ & $\begin{array}{r}-0.132 \\
(0.033) \\
{[0.000]}\end{array}$ \\
\hline
\end{tabular}

(c) Chronic Opioid Users: Total Dosage

\begin{tabular}{|c|c|c|c|}
\hline & $\begin{array}{l}\text { MME for enrollees with } \\
\text { prior duration } \geq 90 \text { days }\end{array}$ & $\begin{array}{l}\text { MME for enrollees with } \\
\text { prior duration } \geq 180 \text { days }\end{array}$ & $\begin{array}{l}\text { MME for enrollees with } \\
\text { prior duration } \geq 360 \text { days }\end{array}$ \\
\hline PDMP & $\begin{array}{c}-0.097 \\
(0.060) \\
{[0.105]}\end{array}$ & $\begin{array}{c}-0.090 \\
(0.062) \\
{[0.146]}\end{array}$ & $\begin{array}{c}-0.136 \\
(0.040) \\
{[0.001]}\end{array}$ \\
\hline
\end{tabular}

(D) Chronic Opioid Users: Individual Dosage

\begin{tabular}{|c|c|c|c|}
\hline & $\begin{array}{c}\text { Per-claim MME, } \\
\text { prior duration } \geq 90 \text { days }\end{array}$ & $\begin{array}{c}\text { Per-claim MME, } \\
\text { prior duration } \geq 180 \text { days }\end{array}$ & $\begin{array}{c}\text { Per-claim MME, } \\
\text { prior duration } \geq 360 \text { days }\end{array}$ \\
\hline PDMP & $\begin{array}{c}-0.025 \\
(0.076) \\
{[0.736]}\end{array}$ & $\begin{array}{c}-0.017 \\
(0.083) \\
{[0.840]}\end{array}$ & $\begin{array}{c}0.037 \\
(0.031) \\
{[0.216]}\end{array}$ \\
\hline Covariates & Yes & Yes & Yes \\
\hline State FE & Yes & Yes & Yes \\
\hline Time FE & Yes & Yes & Yes \\
\hline States & 51 & 51 & 51 \\
\hline Observations & 306 & 306 & 306 \\
\hline
\end{tabular}

Note: Results from Poisson regression. Standard errors clustered at the state level are shown in parentheses below the coefficients. P-values are shown in square parentheses below the coefficients. Covariates include state census population (on a logarithmic scale), state unemployment rate, state per-capita personal income, state percapita GDP, and lagged number of BCBS enrollees in the state (on a logarithmic scale). Data are from the Blue Cross Blue Shield Axis ${ }^{\circledR}$ database. 
before, we do not find any significant reductions in the dosage amount per claim, indicating that physicians do not taper off chronic users by gradually reducing prescription amounts, but instead cut off some patients altogether. This abrupt discontinuation of chronic opioid therapy is concerning given its potentially harmful effects on patients, as well as the possibility that it could induce substitution to illicit drugs.

\subsection{Patient Responses}

\subsubsection{Evasion and Doctor Shopping}

One potential patient response to the supply restriction is to seek prescriptions from multiple doctors, or "doctor shopping." Doctor shopping may also partially explain the results in the previous section: with a PDMP, physicians discover that their patients are already receiving opioid prescriptions from other providers and then refuse to prescribe further. In light of this, obtaining further prescriptions from other in-state physicians may be futile when a PDMP is in place. For this reason, we explicitly investigate whether enrollees engage in doctor shopping behavior with out-of-state physicians. We measure doctor shopping using the number of patients who receive prescriptions from at least three different providers, differentiating between prescriptions from in-state and out-of-state providers.

Since the net value of visiting out-of-state providers is diminished when neighboring states also have PDMPs, we adjust our main specification to interact the PDMP indicator with the percent of neighboring states lacking a PDMP in a given year. Table 4 shows that PDMP introduction reduces the number of patients with three or more in-state prescribers within a three-month window by $16.5 \%$ (column 2), and this effect is not counteracted by neighboring states without PDMPs. The number of patients who receive at least 2 or at least 3 prescriptions from out-of-state prescribers also falls after a PDMP is introduced, however this effect is partially offset in proportion to the percent of neighboring states without PDMPs (columns 4-5). These estimates point to a substantial amount of evasion that depends on the monitoring environment in neighboring states. If we extend the time frame and consider prescriptions from multiple providers within the last six months, we find the same pattern of increases in out-of-state doctor shopping. Patients whose prescriptions are abruptly discontinued try to obtain prescriptions by visiting multiple other health care providers out-of-state.

\subsubsection{Consumption and Drug Substitution}

If individuals who have developed opioid dependence or who misuse opioids are unable to obtain sufficient amounts of opioids via legal prescriptions, an option is to buy diverted prescription drugs or other 
Table 4: The Effect of Prescription Drug Monitoring Programs on Doctor Shopping

\begin{tabular}{|c|c|c|c|c|c|}
\hline & \multicolumn{5}{|c|}{ USERS WITH MULTIPLE PRESCRIBERS WITHIN 3 MONTHS } \\
\hline & (1) & (2) & (3) & (4) & (5) \\
\hline & $3+$ providers & $\begin{array}{l}3+\text { providers } \\
\text { all in-state }\end{array}$ & $\begin{array}{c}3+\text { providers } \\
1+\text { out-of-state }\end{array}$ & $\begin{array}{c}3+\text { providers } \\
2+\text { out-of-state }\end{array}$ & $\begin{array}{c}3+\text { providers } \\
3+\text { out-of-state }\end{array}$ \\
\hline PDMP & $\begin{array}{c}-0.196 \\
(0.049) \\
{[0.000]}\end{array}$ & $\begin{array}{c}-0.165 \\
(0.050) \\
{[0.001]}\end{array}$ & $\begin{array}{c}-0.281 \\
(0.055) \\
{[0.000]}\end{array}$ & $\begin{array}{c}-0.236 \\
(0.048) \\
{[0.000]}\end{array}$ & $\begin{array}{c}-0.187 \\
(0.033) \\
{[0.000]}\end{array}$ \\
\hline$\%$ of neighbor states w/o PDMP & $\begin{array}{c}-0.009 \\
(0.010) \\
{[0.364]}\end{array}$ & $\begin{array}{c}-0.009 \\
(0.010) \\
{[0.368]}\end{array}$ & $\begin{array}{c}-0.013 \\
(0.008) \\
{[0.127]}\end{array}$ & $\begin{array}{c}-0.010 \\
(0.005) \\
{[0.030]}\end{array}$ & $\begin{array}{c}-0.010 \\
(0.004) \\
{[0.010]}\end{array}$ \\
\hline$(\mathrm{PDMP}) *(\%$ of neighbor states w/o PDMP) & $\begin{array}{c}0.010 \\
(0.010) \\
{[0.304]}\end{array}$ & $\begin{array}{c}0.010 \\
(0.010) \\
{[0.319]}\end{array}$ & $\begin{array}{c}0.012 \\
(0.008) \\
{[0.133]}\end{array}$ & $\begin{array}{c}0.009 \\
(0.004) \\
{[0.042]}\end{array}$ & $\begin{array}{c}0.009 \\
(0.004) \\
{[0.014]}\end{array}$ \\
\hline Covariates & Yes & Yes & Yes & Yes & Yes \\
\hline State FE & Yes & Yes & Yes & Yes & Yes \\
\hline Time FE & Yes & Yes & Yes & Yes & Yes \\
\hline States & 51 & 51 & 51 & 51 & 51 \\
\hline Observations & 306 & 306 & 306 & 306 & 306 \\
\hline
\end{tabular}

Note: Results from Poisson regression. Standard errors clustered at the state level are shown in parentheses below the coefficients. Pvalues are shown in square parentheses below the coefficients. Covariates include state census population (on a logarithmic scale), state unemployment rate, state per-capita personal income, state per-capita GDP, and lagged number of BCBS enrollees in the state (on a logarithmic scale). Data are from the Blue Cross Blue Shield Axis ${ }^{\circledR}$ database.

illicit opioids on secondary markets. We use the NSDUH to investigate consumer behavior in response to the supply side restriction. The NSDUH elicits information on whether respondents have used pain relievers without a prescription from a doctor, and whether they use heroin or other types of drugs. Since the market for diverted pain medication dries up quickly as more states introduce PDMPs and curb loose prescribing practices, heroin constitutes a cheaper alternative. We find that the number of people who use pain killers without having a prescription increases by $3 \%$ (Table 5, column 1).

Drug substitution occurs frequently: the number of people who report using heroin increases by $8.5 \%$ (column 2). Drug users also appear to use other substances that are not direct substitutes for opioids. Non-medical use of sedatives or tranquilizers rises by $5.2 \%$. This is largely driven by an increase in use of benzodiazepines, another highly addictive class of medication (columns 3-4). Even though illicit drug use increases for a wide range of substances, there is no increase in the number of people who seek or receive treatment for drug use (column 5).

While these effects are substantial, the relative increases are smaller than the relative reductions in prescriptions. One caveat is that some patients who were previously receiving legitimate opioid prescriptions may have already been using illicit drugs - the NSDUH asks respondents whether they "ever used" a specific drug, effectively measuring incidence instead of prevalence. In light of this, the smaller estimate for prescription drug misuse compared to heroin suggests that pre-PDMP drug misuse was mostly limited to prescription opioids and not heroin, and that PDMPs increase the likelihood of switching to 
Table 5: The Effect of Prescription Drug Monitoring Programs on Opioid Consumption

\begin{tabular}{|c|c|c|c|c|c|}
\hline & \multicolumn{5}{|c|}{ RESPONDENTS DRUG USE BY SUBSTANCE } \\
\hline & (1) & (2) & (3) & (4) & (5) \\
\hline & $\begin{array}{c}\text { Ever used } \\
\text { pain relievers } \\
\text { w/o prescription }\end{array}$ & $\begin{array}{l}\text { Ever used } \\
\text { heroin }\end{array}$ & $\begin{array}{c}\text { Ever used sedatives } \\
\text { or tranquilizers } \\
\text { w/o prescription }\end{array}$ & $\begin{array}{c}\text { Ever used } \\
\text { benzodiazepines }\end{array}$ & $\begin{array}{l}\text { Received treatment } \\
\text { for illicit drug use }\end{array}$ \\
\hline PDMP & $\begin{array}{c}0.029 \\
(0.013) \\
{[0.030]}\end{array}$ & $\begin{array}{c}0.085 \\
(0.051) \\
{[0.094]}\end{array}$ & $\begin{array}{c}0.052 \\
(0.021) \\
{[0.016]}\end{array}$ & $\begin{array}{c}0.053 \\
(0.023) \\
{[0.019]}\end{array}$ & $\begin{array}{c}-0.046 \\
(0.052) \\
{[0.378]}\end{array}$ \\
\hline Covariates & Yes & Yes & Yes & Yes & Yes \\
\hline State FE & Yes & Yes & Yes & Yes & Yes \\
\hline Time FE & Yes & Yes & Yes & Yes & Yes \\
\hline States & 51 & 51 & 51 & 51 & 51 \\
\hline Observations & 306 & 357 & 306 & 306 & 306 \\
\hline
\end{tabular}

Note: Results from Poisson regression. Standard errors clustered at the state level are shown in parentheses below the coefficients. P-values are shown in square parentheses below the coefficients. Covariates include state census population (on a logarithmic scale), state unemployment rate, state per-capita personal income, and state per-capita GDP. Data are from the National Survey on Drug Use and Health (NSDUH). The sample size differs for heroin compared to the other outcomes due to data availability for one additional survey year.

Heroin. As previously, these results are invariant to controlling for other time-varying state policies (see Appendix Table A.14).

The results for drug consumption also permit inference on the rate of substitution between heroin and prescription drugs, $\Delta_{H, P}=\mathrm{d} q_{H} / \mathrm{d} q_{P}$. Based on our relative effects, we first compute the elasticity of substitution between heroin and prescription drugs, $\varepsilon_{H, P}$. Due to the differences in the population base, the magnitude of the elasticity itself is difficult to interpret. We adjust the elasticity by base population to compute the absolute rate of substitution, $\Delta_{H, P}=\varepsilon_{H, P} q_{H} / q_{P}$. Since we observe changes in consumption of prescription drugs for the privately insured only, but adoption of heroin for the general population, we can only bound the elasticity (and the rate of substitution in turn). We apply the law of total expectation to the elasticity, decomposing the effect on prescription drug consumption. This yields

$$
\Delta_{H, P}=\frac{\frac{\partial q_{\mathrm{H}}}{q_{\mathrm{H}}}}{\frac{\partial q_{\mathrm{P}}}{q_{\mathrm{P}}}} \frac{q_{\mathrm{H}}}{q_{\mathrm{P}}}=\frac{\frac{\partial q_{\mathrm{H}}}{q_{\mathrm{H}}}}{\mathbb{P}(\text { Private }) \frac{\partial q_{\mathrm{P}}^{\text {Pivate }}}{q_{\mathrm{P}}^{\text {Private }}}+[1-\mathbb{P}(\text { Private })] \frac{\partial q_{\mathrm{P}}^{\text {Public }}}{q_{\mathrm{P}}^{\text {Public }}}} \frac{q_{\mathrm{H}}}{q_{\mathrm{P}}} .
$$

We insert the known population shares for the privately insured and non-privately insured population based on Census data. We then calculate the bounds based on different assumptions about the effect of PDMP operation on the consumption of prescription drugs. As a lower bound, we assume that all non-privately insured stop taking any prescription opioids. As an upper bound, we assume that the nonprivately insured do not change drug consumption at all. As a middle ground, we assume homogeneous effects: the relative reduction in prescription drug use is the same for the privately and non-privately 
Table 6: Rate of Substitution Between Prescription Opioids and Heroin

\begin{tabular}{lc}
\hline & $\Delta_{H, P}$ \\
\hline Lower bound & -0.06 \\
Upper bound & -0.26 \\
Homogeneous effects & -0.18 \\
Estimate based on Buchmueller and Carey (2018) & -0.24 \\
\hline
\end{tabular}

Note: Based on estimation results from BCBS Axis ${ }^{\circledR}$, NSDUH and Census data.

insured. ${ }^{16}$

Results in the literature tend to suggest smaller effects for the publicly insured population, somewhere between the zero effect assumption for the upper bound and the homogeneous effect. Meara et al. (2016) find no effect of PDMPs using Medicare data. Buchmueller and Carey (2018) find an overall reduction of $2.4 \%$ in the share of Medicare Part D enrollees taking opioids in response to must-access PDMPs, and larger declines for misuse outcomes (5\% reduction in the share of opioid takers with overlapping claims, $6 \%$ for those with more than seven months' supply). We also use their main estimate to compute the rate of substitution. The results are shown in Table 6 .

We find a lower bound for the rate of substitution of about 0.06 , assuming consumption by the publicly insured ceases completely as a response to the PDMP. Conversely, in the opposite extreme case, assuming the change is driven by the privately insured population alone, the estimate is 0.26 . Using the Buchmueller and Carey (2018) estimate for the non-commercially insured population, the effect is still substantial at 0.24 . If we assume homogeneous effects, we estimate a middle-ground of about 0.18 . This implies that for every prescription recipient not receiving opioids due to the PDMP, about 0.18 initiate heroin use (or approximately one out of six prescription users initiates heroin consumption).

Although our substitution estimates for consumption are sizeable, they are smaller than existing substitution estimates for mortality. Specifically, our conversion rate from prescription opioid consumption to heroin consumption is lower than the conversion rate others have found for prescription opioid mortality to heroin mortality. For example, analyzing the reformulation of OxyContin, Evans, Lieber, and Power (2019) find a one-to-one replacement of prescription opioid deaths with heroin deaths. Alpert, Powell, and Pacula (2018) find that per 1 percentage point reduction in OxyContin misuse, heroin mortality increases by 3.1 deaths per 100,000. Given a baseline of about one death per 100,000, this suggests a three-fold increase. The most likely explanation for the difference between consumption and mortality substitution is the high fatality risk associated with heroin specifically compared to prescription opioids.

\footnotetext{
${ }^{16} \mathrm{We}$ assume our estimate for the privately insured also covers the population receiving public benefits through private entities. Alternative assumptions change the bounds estimates slightly.
} 
The large overdose risk compensates for the smaller user base, resulting in a higher substitution estimate for mortality.

Two important notes regarding the interpretation of elasticity estimates are needed. First, the estimates also incorporate effects operating through diversion of opioids to secondary markets. Our estimate covers the response in relation to those observed as receiving opioids through a legal prescription. The rate of substitution estimate includes individuals who were relying on diverted prescription opioids for consumption and therefore do not appear in the prescription data, but who nevertheless initiate heroin use in response to PDMP supply restrictions. This population is likely to be non-negligible in size; survey evidence from the NSDUH suggests that $50 \%$ of people who misused prescription opioids in the last year obtained some of them from friends or relatives. This implies that our estimates in general are a conservative upper bound for the total rate of substitution, as we underestimate the population in the denominator.

Second, with our data it is not possible to verify empirically that those individuals whose lose access to prescription opioids on account of the PDMP are necessarily the same individuals who increase uptake of heroin. This is, however, the most plausible behavior according to the literature. Of those individuals who began abusing opioids in the 2000s, $75 \%$ reported that their first opioid was a prescription drug (Cicero et al., 2014). An estimate for heroin is reported by Jones (2013), who examines national-level general population heroin data and shows that nearly 80 percent of current heroin users used prescription opioids prior to heroin. More generally, the incidence of heroin initiation is approximately 19 times higher among those who reported prior pain reliever use than among those who did not (Muhuri, Gfroerer, and Davies, 2013).

\subsubsection{Street Prices and Purchases}

Lower prescription rates reduce the supply of diverted opioids on the street. At the same time, the reductions should also increase the demand from chronic users addicted to opioids. Both of these factors are likely to drive up prices. At the same time, the substitution towards heroin will lower demand and prices for diverted prescription drugs. Which of these effects prevail is an empirical question. We study this effect using publicly posted price data on street purchases of prescription drugs from streetrx.com. Table 7 shows how street prices measured in $\$ / \mathrm{mg}$ for different opioid and non-opioid drugs react to PDMP introduction. 
Table 7: The Effect of Prescription Drug Monitoring Programs on Drug Prices

\begin{tabular}{|c|c|c|c|c|c|c|c|c|}
\hline & $\begin{array}{c}(1) \\
\text { Oxycodone }\end{array}$ & $\begin{array}{c}\text { (2) } \\
\text { Hydrocodone }\end{array}$ & $\begin{array}{c}\text { (3) } \\
\text { Morphine }\end{array}$ & $\begin{array}{c}(4) \\
\text { Codeine }\end{array}$ & $\begin{array}{c}\text { (5) } \\
\text { Methadone }\end{array}$ & $\begin{array}{c}(6) \\
\text { Benzodiazepines }\end{array}$ & $\begin{array}{c}\text { (7) } \\
\text { PDE5 inhibitors }\end{array}$ & $\begin{array}{c}\text { (8) } \\
\text { Methylphenidate }\end{array}$ \\
\hline PDMP & $\begin{array}{c}0.145 \\
(0.075) \\
{[0.054]}\end{array}$ & $\begin{array}{c}-0.010 \\
(0.056) \\
{[0.860]}\end{array}$ & $\begin{array}{c}0.183 \\
(0.089) \\
{[0.039]}\end{array}$ & $\begin{array}{c}0.225 \\
(0.272) \\
{[0.409]}\end{array}$ & $\begin{array}{c}0.109 \\
(0.239) \\
{[0.647]}\end{array}$ & $\begin{array}{c}0.249 \\
(0.092) \\
{[0.007]}\end{array}$ & $\begin{array}{c}0.001 \\
(0.257) \\
{[0.995]}\end{array}$ & $\begin{array}{c}0.001 \\
(0.162) \\
{[0.994]}\end{array}$ \\
\hline Covariates & Yes & Yes & Yes & Yes & Yes & Yes & Yes & Yes \\
\hline State FE & Yes & Yes & Yes & Yes & Yes & Yes & Yes & Yes \\
\hline Time FE & Yes & Yes & Yes & Yes & Yes & Yes & Yes & Yes \\
\hline States & 51 & 51 & 51 & 51 & 51 & 51 & 51 & 51 \\
\hline Observations & 255 & 255 & 250 & 227 & 235 & 255 & 207 & 254 \\
\hline
\end{tabular}

Note: Results from Poisson regression. Prices are standardized and measured in \$/mg. Standard errors clustered at the state level are shown in parentheses below the coefficients. P-values are shown in square parentheses below the coefficients. Covariates include state census population (on a logarithmic scale), state unemployment rate, state per-capita personal income, state per-capita GDP. Data are from the StreetRx database. 
We find that the street price of oxycodone increases by about $15 \%$ following tighter prescription drug regulation. For morphine, we find a similar effect of about 18\%. Effects for Codeine and Methadone are in a similar range but noisy and insignificant. We do not find any effect on hydrocodone. Mirroring the results from the consumption data, we also find increases in the prices of benzodiazepines. We also conduct a series of placebo checks using prescription drugs that should be unaffected by PDMPs: PDE5 inhibitors (e.g., Sildenafil/Viagra, Tadalafil/Cialis) and Methylphenidate (Ritalin). Reassuringly, we do not find any effect on the street prices of these substances. Both estimates are indistinguishable from zero.

\subsection{Health Consequences of Drug Substitution}

\subsubsection{Mortality}

We now focus on the analysis of opioid-related mortality. The mortality results are shown in Table 8 , divided into two sets. The first set (columns 1 and 2) considers the entire time period, mixing both ICD-9 and ICD-10 classifications. In this first set we distinguish between all fatal opioid poisonings (overdoses) and drug-related deaths due to opioid dependence. The second set of results (columns 3 to 9) focuses on the ICD-10 period, i.e., 1999-2017. The advantage of the second set of results is that we can disentangle the opioid category into its subgroups and thus examine how mortality due to each specific opioid derivate is affected by a PDMP introduction. We also focus on the sum between heroin and synthetic opioid deaths because fentanyl or heroin/fentanyl mixtures are often illicitly sold as heroin. Finally, we analyze composition changes directly by using the ratio of heroin deaths over total opioid deaths as the dependent variable (column 8).

PDMP introduction has no effect on aggregate opioid mortality for the period 1993-2017 (column 1). Regarding mortality due to long-term use of opioids (column 2), we also cannot reject the null hypothesis that PDMP exposure has no effect on this type of opioid mortality. Note that there might be two countervailing effects induced by the PDMP introduction: PDMPs may reduce direct mortality from prescription drugs, while increasing mortality from illicit substitute drugs at the same time. If both mortality estimates cannot be separated clearly in the data, this would also lead to a noisy estimate centered around zero.

To resolve this issue, we consider the period 1999-2017, where we can isolate each type of opioid in the ICD-10 data (columns 3 through 8). Column 3 replicates column 1 for the restricted time period and we still find an effect indistinguishable from zero. When examining the single classes of opioids, we find that the introduction of a PDMP significantly reduces mortality due to semi-synthetic opioids (column 
Table 8: The Effect of Prescription Drug Monitoring Programs on Mortality

Mortality BY CAUSE OF DEATH

\begin{tabular}{|c|c|c|c|c|c|c|c|c|}
\hline & \multicolumn{2}{|c|}{ 1993-2017 (ICD-9 and ICD-10) } & \multicolumn{6}{|c|}{ 1999-2017 (ICD-10) } \\
\hline & (1) & (2) & (3) & (4) & (5) & (6) & (7) & (8) \\
\hline & $\begin{array}{c}\text { All } \\
\text { opioids }\end{array}$ & $\begin{array}{c}\text { Opioid } \\
\text { dependence }\end{array}$ & $\begin{array}{c}\text { All } \\
\text { opioids }\end{array}$ & $\begin{array}{l}\text { Semi-synthetic } \\
\text { opioids }\end{array}$ & Heroin & $\begin{array}{l}\text { Heroin or } \\
\text { synthetic }\end{array}$ & Methadone & $\begin{array}{l}\text { Share } \\
\text { heroin }\end{array}$ \\
\hline PDMP & $\begin{array}{c}-0.006 \\
(0.065) \\
{[0.837]}\end{array}$ & $\begin{array}{c}-0.036 \\
(0.231) \\
{[0.643]}\end{array}$ & $\begin{array}{c}0.014 \\
(0.063) \\
{[0.598]}\end{array}$ & $\begin{array}{c}-0.073 \\
(0.053) \\
{[0.009]}\end{array}$ & $\begin{array}{c}0.106 \\
(0.097) \\
{[0.003]}\end{array}$ & $\begin{array}{c}0.140 \\
(0.090) \\
{[0.000]}\end{array}$ & $\begin{array}{c}-0.014 \\
(0.056) \\
{[0.489]}\end{array}$ & $\begin{array}{c}0.092 \\
(0.130) \\
{[0.014]}\end{array}$ \\
\hline Covariates & Yes & Yes & Yes & Yes & Yes & Yes & Yes & Yes \\
\hline State FE & Yes & Yes & Yes & Yes & Yes & Yes & Yes & Yes \\
\hline Time FE & Yes & Yes & Yes & Yes & Yes & Yes & Yes & Yes \\
\hline States & 51 & 51 & 51 & 51 & 51 & 51 & 51 & 51 \\
\hline Observations & 1,275 & 1,275 & 969 & 969 & 969 & 969 & 969 & 969 \\
\hline
\end{tabular}

Note: Results from Poisson regression. Standard errors clustered at the state level are shown in parentheses below the coefficients. Randomization inference p-values are shown in square parentheses below the coefficients (1,000 resampling replications). Covariates include state census population (on a logarithmic scale), state unemployment rate, state per-capita personal income, and state per-capita GDP. Data are from the National Vital Statistics System (NVSS).

4). This effect has a magnitude of $-7.3 \%$ and is statistically significant at the $1 \%$ level. The category semi-synthetic opioids includes popular prescription medications such as oxycodone (e.g., OxyContin, Percocet), hydrocodone (Vicodin), and hydromorphone (Dilaudid), indicating that PDMPs achieve the goal of reducing mortality due to opioid pain medications. But do PDMPs induce a substitution effect toward illicit opioids? Columns 5 and 6 show the results for heroin mortality and heroin plus fully synthetic opioid mortality. Both coefficients are positive, sizable, and statistically significant at the $1 \%$ level. Overall, the results indicate that while PDMPs reduce mortality rates due to opioid medications, they also lead to an increase in mortality due to heroin and synthetic opioids. The increase in heroin and fentanyl mortality fully offsets the decrease in mortality due to prescription opioids. In column 8 , we show further evidence of change in the composition of deaths by using heroin's share of all opioid deaths as the dependent variable. The share of deaths due to heroin increases by $9.2 \%$ upon PDMP introduction. As we show in Table A.15 in the appendix, these mortality patterns are not driven by other state policies.

Finally, we find no effect on methadone mortality (column 7), which is expected, as methadone is frequently used for medication treatment of OUD and its effects differ from those of heroin or more conventional opioid medications. In special cases, methadone is prescribed for cancer or other chronic pain when side effects of other opioids limit dosage escalation or pain remains poorly controlled. However, while methadone has a similar analgesic effect, it does not cause euphoria compared to morphine, heroin, oxycodone or similar drugs. As such, it does not constitute an attractive alternative for recreational use. 
(A) All hospitalizations: poisonings

\begin{tabular}{cccccc} 
& $(1)$ & $(2)$ & $(3)$ & $(4)$ & $(5)$ \\
All opioids & Opioid medication & Heroin & Other/unspecified & $\begin{array}{c}(5) \\
\text { Share heroin }\end{array}$ \\
\cline { 2 - 6 } & -0.010 & -0.067 & 0.076 & 0.047 & 0.130 \\
& $(0.012)$ & $(0.013)$ & $(0.028)$ & $(0.024)$ & $(0.043)$ \\
& {$[0.392]$} & {$[0.000]$} & {$[0.006]$} & {$[0.054]$} & {$[0.002]$} \\
\hline
\end{tabular}

(B) EMERGENCY HOSPITALIZATIONS: POISONINGS

\begin{tabular}{|c|c|c|c|c|c|}
\hline & $\begin{array}{c}(1) \\
\text { All opioids }\end{array}$ & $\begin{array}{c}(2) \\
\text { Opioid medication }\end{array}$ & $\begin{array}{l}(3) \\
\text { Heroin }\end{array}$ & $\begin{array}{c}(4) \\
\text { Other/unspecified }\end{array}$ & $\begin{array}{c}(5) \\
\text { Share heroin }\end{array}$ \\
\hline PDMP & $\begin{array}{c}-0.006 \\
(0.015) \\
{[0.702]}\end{array}$ & $\begin{array}{c}-0.061 \\
(0.015) \\
{[0.000]}\end{array}$ & $\begin{array}{c}0.108 \\
(0.032) \\
{[0.001]}\end{array}$ & $\begin{array}{c}0.035 \\
(0.027) \\
{[0.208]}\end{array}$ & $\begin{array}{c}0.142 \\
(0.048) \\
{[0.003]}\end{array}$ \\
\hline Covariates & Yes & Yes & Yes & Yes & Yes \\
\hline Hospital FE & Yes & Yes & Yes & Yes & Yes \\
\hline Time FE & Yes & Yes & Yes & Yes & Yes \\
\hline Hospitals & 2,973 & 2,973 & 2,973 & 2,973 & 2,973 \\
\hline Observations & 16,369 & 16,369 & 16,369 & 16,369 & 16,369 \\
\hline
\end{tabular}

Note: Results from Poisson regression. Standard errors clustered at the hospital level are shown in parentheses below the coefficients. P-values are shown in square parentheses below the coefficients. Covariates include hospital size (on a logarithmic scale), state census population (on a logarithmic scale), state unemployment rate, state per-capita personal income, and state per-capita GDP. Data are from the National Inpatient Sample (NIS).

\subsubsection{Hospitalizations}

Given the mortality results in the previous section, we now turn to the analysis of hospitalizations. Hospitalizations constitute a more frequent outcome and are a reliable measure of public health and related morbidity changes. At the same time, hospitalizations are associated with non-trivial health care spending, providing a broader, relevant measure of population health and costs. In contrast, mortality, while costly, is a low incidence, terminal outcome.

Table 9 presents the results. We first focus on all types of hospitalizations, i.e., inpatient stays, both scheduled (e.g., withdrawal treatment, drug-related illnesses and infections) and those resulting from emergency admission (e.g., overdoses). In a second step, we repeat the analysis focusing on emergency admissions only.

Looking at the number of hospitalizations for all opioids in panel A, column (1), we find no effect of PDMP exposure on hospitalizations. However, once we disaggregate hospitalization into those driven by prescription opioid medications, and those due to heroin, we find a pattern of opposing incidence effects. PDMP introductions reduce hospitalizations due to prescription opioids by $6.7 \%$ (column 2). At the same time, hospitalizations due to heroin increase by $7.6 \%$ (column 3). This opposing pattern indicates that 
some opioid users change their consumption pattern, substituting illicit drugs for prescription medication. A similar picture arises for the share of hospitalizations that are due to heroin (column 5). The share of hospitalizations due to illicit drug consumption increases by $13 \%$. All estimates are highly significant at conventional levels. The composition change slightly affects the residual category of opioids (by 4.7\%). This category includes Fentanyl, but potentially also other drugs that are negatively affected by the restrictions, explaining the moderate effect. As previously, these patterns are not driven by other state policies (see Table A.15 in the appendix).

When we restrict our attention to emergency hospitalizations only (panel B), the pattern of results is exacerbated for heroin poisonings. While the PDMP coefficient for all opioid hospitalizations is still statistically indistinguishable from zero and the coefficient for prescription medication is quite similar to that in panel A, the estimates for heroin are substantially larger (column 3). We observe an $11 \%$ increase in heroin hospitalizations, corresponding to about a $6 \%$ of a standard deviation increase in inpatient-stay hospitalizations per year. Moreover, heroin's share of emergency hospitalizations increases by $14 \%$.

This latter set of estimates underscores the substantial shift of prescription opioid users towards heroin and illicit markets, substituting for prescription use with a more potent substance of the same drug class. Moreover, the results emphasize the dangers of consuming street drugs, whose potency and active ingredients are often unknown and vary drastically. In contrast to this, the consumption of prescription drugs, manufactured by pharmaceutical companies in sterile environments, with strict quality control and standardization of dose and potency, is associated with fewer health risks, as users can easily ascertain the drug amounts they consume. In addition, heroin is often consumed through routes that carry additional risks (i.e., injection, smoking), which further exacerbate the health risks inherent to illicit drugs. Since our results are based on measures of drug poisonings, we are likely to underestimate the real health care costs as we do not capture other complications linked to drug use (e.g., infections).

One important advantage of using the NIS data is that it is possible to examine each hospitalization in detail. This additional analysis allows us to understand the underlying mechanisms by focusing on two dimensions. The first dimension is hospital costs. The composition change in hospitalizations potentially influences both hospital charges and length of stay. The second dimension is patient characteristics, where we investigate which type of patient (gender, ethnicity) is driving the results presented previously. Overall, the additional analyses are key information for policy, in order to better target prevention and treatment campaigns when supply restrictions are imposed.

Table 10 shows the results for hospital costs, divided into hospital charges in inflation-adjusted 2017dollars (panel A) and length of stay (panel B). In terms of total charges, we find that charges associated 
with heroin poisonings increase by $21.8 \%$ after PDMP introduction. This large and significant increase is likely driven by the additional hospitalizations due to heroin poisonings and not by an increase in treatment costs, because the share of charges due to heroin (column 5) is very similar to the effect of PDMPs on the share of heroin poisonings over total opioid cases (Table 9, column 5). We observe no statistically significant change in hospital charges for opioid medication or other/unspecified opioids. The net effect of PDMPs on hospital charges is positive: the total costs associated with all opioid poisonings increase by 3\% upon PDMP introduction. This net effect amounts to approximately $\$ 7,000$ per hospitalyear and is - as the results in Table 9 imply - primarily driven by an increase in the number of heroin poisonings.

In terms of the total number of hospital days (Table 10, panel B), we find a strong increase for poisonings due to both heroin (25.5\%) and other/unspecified opioids (10.9\%). These increases are completely offset by a decrease in the total number of hospital days due to opioid medication poisonings (12.0\%), resulting in a zero net effect for all opioids poisonings (column 1). Similar to charges, the heroin share for total hospital days (column 5) is comparable to the heroin share for hospitalizations presented in Table 9. Note that these are effects on total hospital days, not per-case length of stay. For per-case length of stay, we find a smaller intensive margin increase of 0.11 for heroin hospitalizations (not reported). This pattern of findings suggests a change in the marginal consumer of heroin or in consumption habits. Novel users are inexperienced in the consumption of heroin and more likely to overdose severely, leading to longer hospitalization spells.

When looking at patient characteristics (Appendix Table A.12), we find that both the reduction in opioid hospitalizations and the increase in heroin hospitalizations are slightly larger for men than for women. Regarding race - classified as white or non-white patients - we find significant effects of PDMPs on heroin and opioid medication poisonings exclusively for white patients. The effects for non-white patients are much smaller in relative terms and not statistically significant. ${ }^{17}$

\subsubsection{Pill Mills in Florida}

Pill mills are facilities resembling specialty pain care clinics that prescribe and/or dispense excessive quantities of opioids, beyond that which would be considered medically appropriate. At these facilities, physicians typically prescribe controlled substances without proper examination, diagnosis, documentation, or background checks of patients' medical history. Most pill mills imitate pain clinics and specialize in prescribing opioids and benzodiazepines. Clients usually pay cash to obtain prescriptions. Since pre-

\footnotetext{
${ }^{17}$ A more disaggregated analysis of racial categories does not reveal any other significant results.
} 
(A) Hospitalizations: Charges

\begin{tabular}{cccccc} 
& $\begin{array}{c}(1) \\
\text { All opioids }\end{array}$ & Opioid medication & $\begin{array}{c}(3) \\
\text { Heroin }\end{array}$ & $\begin{array}{c}(4) \\
\text { Other/unspecified }\end{array}$ & $\begin{array}{c}(5) \\
\text { Share heroin }\end{array}$ \\
\cline { 2 - 6 } PDMP & 0.030 & -0.031 & 0.218 & 0.038 & 0.143 \\
& $(0.017)$ & $(0.020)$ & $(0.044)$ & $(0.037)$ & $(0.055)$ \\
& {$[0.088]$} & {$[0.117]$} & {$[0.000]$} & {$[0.295]$} & {$[0.009]$} \\
\hline
\end{tabular}

(B) Hospitalizations: Total Hospital Days

\begin{tabular}{|c|c|c|c|c|c|}
\hline & $\begin{array}{c}\text { (1) } \\
\text { All opioids }\end{array}$ & $\begin{array}{c}(2) \\
\text { Opioid medication }\end{array}$ & $\begin{array}{l}(3) \\
\text { Heroin }\end{array}$ & $\begin{array}{c}\text { (4) } \\
\text { Other/unspecified }\end{array}$ & $\begin{array}{c}\text { (5) } \\
\text { Share heroin }\end{array}$ \\
\hline PDMP & $\begin{array}{c}-0.018 \\
(0.016) \\
{[0.260]}\end{array}$ & $\begin{array}{c}-0.120 \\
(0.018) \\
{[0.000]}\end{array}$ & $\begin{array}{c}0.255 \\
(0.043) \\
{[0.000]}\end{array}$ & $\begin{array}{c}0.109 \\
(0.042) \\
{[0.010]}\end{array}$ & $\begin{array}{c}0.159 \\
(0.059) \\
{[0.007]}\end{array}$ \\
\hline Covariates & Yes & Yes & Yes & Yes & Yes \\
\hline Hospital FE & Yes & Yes & Yes & Yes & Yes \\
\hline Time FE & Yes & Yes & Yes & Yes & Yes \\
\hline Hospitals & 2,973 & 2,973 & 2,973 & 2,973 & 2,973 \\
\hline Observations & 16,369 & 16,369 & 16,369 & 16,369 & 16,369 \\
\hline
\end{tabular}

Note: Results from Poisson regression. Standard errors clustered at the hospital level are shown in parentheses below the coefficients. P-values are shown in square parentheses below the coefficients. Covariates include hospital size (on a logarithmic scale), state census population (on a logarithmic scale), state unemployment rate, state per-capita personal income, and state per-capita GDP. Data are from the National Inpatient Sample (NIS).

scriptions are easy to obtain, and can be obtained from multiple such facilities, pill mills are likely to have facilitated the proliferation of opioids and addiction. Anecdotal evidence suggests that pill mill prescriptions have been used by both consumers and drug dealers as a source of drug supply.

PDMPs challenge the operation of pill mills: excessive prescribing that promotes drug addiction rather than curing or relieving pain is a violation of medical ethics. Physicians may face professional consequences and prosecution if found out, and facilities will be shut down. When physicians have to register opioid prescriptions in a PDMP that can also be accessed by law enforcement, providers with excessive opioid prescribing can be identified easily, threatening pill mills' business model and continued operation.

One U.S. state that has been notorious for widespread operation of pill mills and easy access to prescription drugs is Florida (e.g., Higham, Horwitz, and Rich, 2019). Other Southern states introduced PDMPs (or other legislation to limit pill mill operation) years before Florida did so in 2011. Florida became known as the "pill mill capital" of the U.S. According to the DEA, Florida had over 900 unregulated pain management clinics in 2010, employing 90 of the top 100 oxycodone-dispensing physicians in the United States. Of the top 50 oxycodone-dispensing clinics across the country, 49 were located in 
Figure 3: The Impact of PDMPs and the Closure of Florida Pill Mills on Prescription Drug Consumption and Heroin Mortality

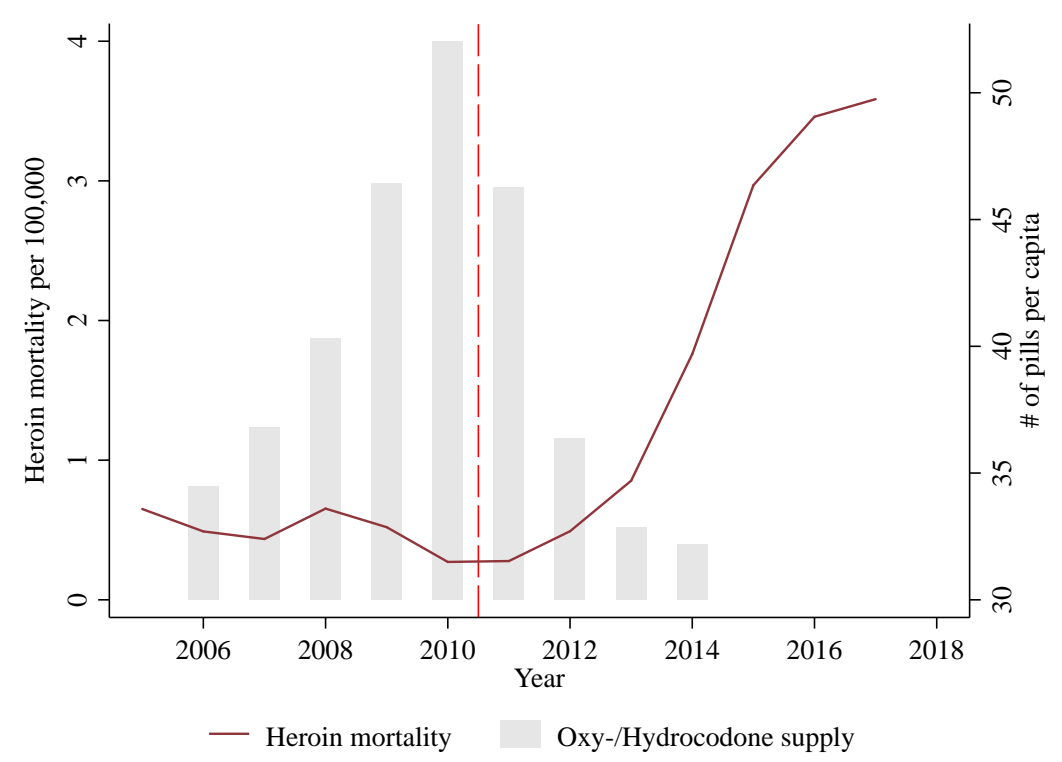

Note: Oxy-/Hydrocodone pills dispensed per capita and heroin mortality per 100,000 of population over time. Sources: DEA ARCOS, National Vital Statistics System.

Florida, selling in excess of a million oxycodone pills a month (Florida Board of Medicine, 2014). For this reason, we conduct a case study of how pill mills in Florida have sustained drug use and addiction, as it clearly highlights the impact of an electronic PDMP on prescribing behavior and its unintended consequences when opioids are widely prescribed.

We track the dispensation of oxy-/hydrocodone and heroin mortality (based on the ARCOS and NVSS data) before and after the state of Florida begins operation of the mandatory E-FORCSE PDMP reporting system. The results are shown in Figure 3. We find that immediately following the introduction of the PDMP, dispensation of oxy- and hydrocodone begins to decrease, falling by about $30 \%$ over four years. We also observe a steep increase in heroin mortality. From a relatively low base, heroin mortality increases five-fold between 2010 and 2015. The comparatively large increase suggests the marginal consumer switching to heroin is unfamiliar with its consumption. The high fatality rate is likely to be explained by users being accustomed to unadulterated prescription drugs with consistent dosage amounts and unfamiliar with the higher potency of heroin and its consumption risks.

\subsubsection{Trends and Dynamics}

In this final section, we take a dynamic perspective on the issue of drug substitution. In terms of preventing addiction, restricting easy access to prescription opioids is arguably a beneficial policy in the long-run - if considered in isolation. However, as our results indicate, drug users switching to heroin 
can be associated with significant public health costs in the short-run. Moreover, there is the possibility that increases in both demand and supply of heroin following PDMP introduction sufficiently increase exposure to illicit drugs in at-risk subpopulations such that there is a net increase in drug consumers, potentially mitigating or even reversing the effects of the access restriction. To investigate this issue, we conduct event study estimations for the major health outcomes. Results are shown in Appendix Figures A.2 and A.3. Note that these analyses also implicitly test for significant pre-trends, and we find no systematic pre-trend effect that might violate the key identification strategy discussed in the empirical strategy section.

Regarding mortality, we find that mortality due to semi-synthetic prescription opioids is permanently lowered (Appendix Figure A.2, panel B). This suggests that PDMPs are effective in reducing mortality due to prescription medications. However, as our previous analysis indicates, we also observe a concurrent increase in mortality due to heroin and fentanyl (Appendix Figure A.2, panel C). The event-study suggests that this effect occurs immediately and remains stable over time. Overall, opioid mortality does not seem to be strongly affected in the medium- to longer-term (Appendix Figure A.2, panel A). If anything, the results suggest a minor net decline over time.

For hospitalizations, the patterns for hospitalizations due to all opioid poisonings and poisonings due to prescription opioids are very similar to those for mortality. While hospitalizations due to all opioid poisonings are largely stable, those due to prescription opioids exhibit a steady decline over time after a PDMP is introduced. For heroin poisonings, we observe a steady increase in the number of hospitalizations over time.

Considering the pattern of results for heroin mortality and hospitalizations together in context, our interpretation is that as drug users unfamiliar with street drugs and consumption by injection switch to heroin, fatal overdoses that bypass hospitalization spike initially. As users become acquainted with heroin, dosage concentrations and the associated consumption risks, mortality stabilizes while hospitalizations increase. At the same time, paramedics and first responders become more accustomed to treating overdose cases, further increasing the likelihood that an overdose is non-fatal and results in hospitalization. Similarly, the proliferation of naloxone to treat overdose cases increases with the prevalence of heroin consumption, further increasing the likelihood of hospitalizations compared to fatalities. 


\section{Conclusion}

Public health officials have called the current opioid epidemic the worst drug crisis in American history (Dowell, Haegerich, and Chou, 2016). In 2021, drug overdose deaths during the latest 12-month period exceeded 100,000 for the first time in history, corresponding to a mortality rate of more than 30 per 100,000 . Our data show that one fifth of all initial opioid prescription claims with the largest commercial insurance association in the U.S. exceed the CDC's prescribing limit guidelines. Unintentional poisoning is now the fatal injury with the most years of potential life lost before age 65, surpassing one million years of potential life lost. ${ }^{18}$ It is thus crucial to study the mechanisms behind the opioid epidemic and understand which policies are effective against it.

In this paper, we focus on PDMPs as an important supply-side policy to prevent prescription opioid misuse and addiction. We find that PDMPs are effective in permanently reducing both the number of overall and high-dose/long-duration scripts by about 13\%, and successfully limit exposure of opioidnaive patients. However, prescribers respond almost exclusively on the extensive margin, reducing the number of prescriptions, but not the strength or duration of a prescription. This result matches the findings by Zhu et al. (2019) and Buchmueller, Carey, and Meille (2020), who note that prescribers respond to the opioid crisis by ceasing to start some patients on opioids altogether, rather than prescribing opioids at safer doses and durations. In light of the fact that many prescriptions are considered unnecessarily strong, this result calls for further research on physician's prescribing behavior. Moreover, we find that prescribers frequently cease prescribing further opioids to chronic users. Abrupt discontinuation causes distress and has been linked to an array of negative outcomes, including overdose, suicide, and potential drug substitution. Indeed, we find that users react by engaging in doctor shopping to evade the restrictions. They also seek other alternatives: we document a substantial increase in the number of first-time heroin users, as well as users of other illicit drugs.

We establish that PDMPs achieve their intended goal: fewer people initiate opioid treatment, and opioid-naive people are shielded from exposure. Nonetheless, our study reveals that PDMPs also have important unintended consequences. As access to prescription medication is being restricted, some drug users turn to heroin and illicit drugs. The resulting increases in mortality and hospitalizations due to heroin fully reverse the reductions due to prescription opioids. Opioid hospitalizations are associated with more expensive hospital stays, leading to a net increase in hospitalization costs. In addition, our analysis reveals that a large part of the policy incidence falls on commercial enrollees, suggesting that analyses relying on Medicaid or Medicare claims data alone are missing an important part of the picture.

\footnotetext{
${ }^{18}$ Calculations provided by the CDC, available at the following link: http://webappa.cdc.gov.
} 
Moreover, our event study analysis reveals that mortality effects are concentrated in the first few years after PDMP introduction. As heroin use becomes more established, the number of lethal cases stabilizes and hospitalizations increase further.

Given the magnitude of the estimates, our findings have important policy implications. Restricting access to prescription opioids when they are not medically necessary, and/or when they are not being prescribed safely, is sensible policy. Nevertheless, restricting access to comparatively less risky drugs for a large population of people who are opioid-dependent has important negative unintended consequences. Expecting long-term users to simply stop consuming drugs because access is restricted is unrealistic, especially if substitute drugs are cheaply available on secondary markets. Problems are amplified since illicit substitute drugs are associated with substantially increased health and fatality risks. Our main results indicate that drug substitution partially reverses the intended effects of PDMPs and is associated with significant public health and monetary costs. Future research is needed to assess how much of this effect is temporary. This requires a better understanding of whether the current heroin market is limited to those cohorts of consumers which were exposed to the change in access laws, or whether the increased availability of heroin induces new consumers without any history of prescription opioid use to adopt heroin.

To conclude, our study finds that restricting access to prescription opioids curtails their use to some extent, but also causes a substantial fraction of patients to seek riskier illicit opioids such as heroin. This points to a need for pairing supply-side restrictions with policies to improve access to evidence-based treatment for OUD and related social service supports. Medications to treat OUD are a far safer substitute than illicit opioids, but treatment capacity has historically been far from adequate in the U.S. (e.g., Volkow, 2018; Volkow et al., 2014; Volkow and McLellan, 2016). ${ }^{19}$ Our findings indicate that improving access to safer substitutes such as OUD treatment may mitigate the negative unintended consequences of supply-side restrictions on prescription opioids.

\footnotetext{
${ }^{19}$ In additional analyses, we split our estimation sample by the number of Buprenorphine-waivered providers in each state as a measure of OUD treatment capacity. Although the analysis is underpowered, the results suggest that effects for both heroin consumption and heroin mortality are comparatively smaller in states with larger treatment capacity.
} 


\section{References}

Alpert, Abby, Sarah Dykstra, and Mireille Jacobson. 2020. "How do prescription drug monitoring programs reduce opioid prescribing? The role of hassle costs versus information." NBER Working Paper No. 27584, National Bureau of Economic Research.

Alpert, Abby, William Evans, Ethan Lieber, and David Powell. 2019. "Origins of the Opioid Crisis and Its Enduring Impacts.” NBER Working Paper No. 26500, National Bureau of Economic Research.

Alpert, Abby, David Powell, and Rosalie Liccardo Pacula. 2018. "Supply-side drug policy in the presence of substitutes: evidence from the introduction of abuse-deterrent opioids." American Economic Journal: Economic Policy 10 (4):1-35.

Brady, Joanne, Hannah Wunsch, Charles DiMaggio, Barbara Lang, James Giglio, and Guohua Li. 2014. "Prescription drug monitoring and dispensing of prescription opioids." Public Health Reports 129 (2):139-147.

Brummett, Chad, Jennifer Waljee, Jenna Goesling, Stephanie Moser, Paul Lin, Michael Englesbe, Amy Bohnert, Sachin Kheterpal, and Brahmajee Nallamothu. 2017. "New persistent opioid use after minor and major surgical procedures in US adults.” JAMA Surgery 152 (6):e170504-e170504.

Buchmueller, Thomas and Colleen Carey. 2018. "The effect of prescription drug monitoring programs on opioid utilization in Medicare." American Economic Journal: Economic Policy 10 (1):77-112.

Buchmueller, Thomas, Colleen Carey, and Giacomo Meille. 2020. "How well do doctors know their patients? Evidence from a mandatory access prescription drug monitoring program." Health Economics 29 (9):957-974.

Callaway, Brantly and Pedro Sant'Anna. 2020. "Difference-in-differences with multiple time periods." Journal of Econometrics .

Case, Anne and Angus Deaton. 2015. "Rising morbidity and mortality in midlife among white non-Hispanic Americans in the 21st century." Proceedings of the National Academy of Sciences 112 (49):15078-15083.

. 2017. "Mortality and morbidity in the 21st century." Brookings Papers on Economic Activity 2017:397-476.

— 2018. "Deaths of despair redux: a response to Christopher Ruhm." Tech. rep., National Bureau of Economic Research.

2020. Deaths of Despair and the Future of Capitalism. Princeton University Press.

Caulkins, Jonathan. 2001. "Drug prices and emergency department mentions for cocaine and heroin." American Journal of Public Health 91 (9):1446-1448.

CDC. 2016. "CDC Guideline for Prescribing Opioids for Chronic Pain - Factsheet.” Tech. rep., Centers for Disease Control and Prevention.

—. 2020. "U.S. Opioid Dispensing Rate Maps.” URL https://www.cdc.gov/drugoverdose/ maps/rxrate-maps.html.

. 2021. "Provisional drug overdose death counts." URL https://www.cdc.gov/nchs/nvss/ vsrr/drug-overdose-data.htm.

Ciani, Emanuele and Paul Fisher. 2019. "Dif-in-dif estimators of multiplicative treatment effects." Journal of Econometric Methods 8 (1). 
Cicero, Theodore and Matthew Ellis. 2015. "Abuse-deterrent formulations and the prescription opioid abuse epidemic in the United States: Lessons learned from OxyContin." JAMA Psychiatry 72 (5):424430 .

Cicero, Theodore, Matthew Ellis, Hilary Surratt, and Steven Kurtz. 2014. "The changing face of heroin use in the United States: A retrospective analysis of the past 50 years." JAMA Psychiatry 71 (7):821826.

Currie, Janet and Hannes Schwandt. 2020. "The opioid epidemic was not caused by economic distress but by factors that could be more rapidly addressed." NBER Working Paper No. 27544, National Bureau of Economic Research.

Davis, Corey, Matthew Pierce, and Nabarun Dasgupta. 2014. "Evolution and convergence of state laws governing controlled substance prescription monitoring programs, 1998-2011." American Journal of Public Health 104 (8):1389-1395.

De Chaisemartin, Clément and Xavier d'Haultfoeuille. 2020. "Two-way fixed effects estimators with heterogeneous treatment effects.” American Economic Review 110 (9):2964-2996.

DiNardo, John and Thomas Lemieux. 2001. "Alcohol, marijuana, and American youth: the unintended consequences of government regulation." Journal of Health Economics 20 (6):991-1010.

Dobkin, Carlos and Nancy Nicosia. 2009. "The war on drugs: methamphetamine, public health, and crime." American Economic Review 99 (1):324-349.

Dobkin, Carlos, Nancy Nicosia, and Matthew Weinberg. 2014. "Are supply-side drug control efforts effective? Evaluating OTC regulations targeting methamphetamine precursors." Journal of Public Economics 120:48-61.

Dowell, Deborah, Tamara Haegerich, and Roger Chou. 2016. "CDC guideline for prescribing opioids for chronic pain - United States, 2016.” MMWR Recommendations and Reports 65 (1):1-49.

Evans, Mary, Matthew Harris, and Lawrence Kessler. 2020. "The hazards of unwinding the prescription opioid epidemic: implications for child abuse and neglect." Research Paper No. 3582060, Claremont McKenna College Robert Day School of Economics and Finance.

Evans, William, Ethan Lieber, and Patrick Power. 2019. "How the reformulation of OxyContin ignited the heroin epidemic." Review of Economics and Statistics 101 (1):1-15.

Fally, Thibault. 2015. "Structural gravity and fixed effects." Journal of International Economics 97 (1):76-85.

Fields, Howard. 2011. “The Doctor's Dilemma: opiate analgesics and chronic pain." Neuron 69 (4):591-594.

Fisher, Ronald. 1935. The Design of Experiments. Oliver and Boyd, Edinburgh (UK).

Florida Board of Medicine. 2014. "Prescription Drug Monitoring Program.” Latest News, Florida Board of Medicine.

Gihleb, Rania, Osea Giuntella, and Ning Zhang. 2019. "The effects of mandatory Prescription Drug Monitoring Programs on foster care admissions." Journal of Human Resources .

Goodman-Bacon, Andrew. 2021. "Difference-in-differences with variation in treatment timing." Journal of Econometrics .

Grecu, Anca, Dhaval Dave, and Henry Saffer. 2019. "Mandatory access Prescription Drug Monitoring Programs and prescription drug abuse." Journal of Policy Analysis and Management 38 (1):181-209. 
Griffin, Beth Ann, Megan Schuler, Elizabeth Stuart, Stephen Patrick, Elizabeth McNeer, Rosanna Smart, David Powell, Bradley Stein, Terry Schell, and Rosalie Liccardo Pacula. 2020. "Variation in performance of commonly used statistical methods for estimating effectiveness of state-level opioid policies on opioid-related mortality." Working Paper 27029, National Bureau of Economic Research.

Grossmann, Volker and Holger Strulik. 2021. "Illicit drugs and the decline of the middle class." Journal of Economic Behavior \& Organization 183:718-743.

Haegerich, Tamara, Leonard Paulozzi, Brian Manns, and Christopher Jones. 2014. "What we know, and don't know, about the impact of state policy and systems-level interventions on prescription drug overdose." Drug and Alcohol Dependence 145:34-47.

Harrell, A. V. 1997. "The validity of self-reported drug use data: the accuracy of responses on confidential self-administered answered sheets." NIDA Research Monograph 167:37-58.

Hess, Simon. 2017. "Randomization inference with Stata: A guide and software." The Stata Journal 17 (3):630-651.

Higham, Scott, Sari Horwitz, and Steven Rich. 2019. "76 billion opioid pills: Newly released federal data unmasks the epidemic." Washington Post .

Horwitz, Jill, Corey Davis, Lynn McClelland, Rebecca Fordon, and Ellen Meara. 2018. "The problem of data quality in analyses of opioid regulation: The case of Prescription Drug Monitoring Programs." NBER Working Paper 24947, National Bureau of Economic Research.

Jones, Christopher. 2013. "Heroin use and heroin use risk behaviors among nonmedical users of prescription opioid pain relievers - United States, 2002-2004 and 2008-2010." Drug and Alcohol Dependence 132 (1-2):95-100.

Jones, Christopher, Margaret Warner, Holly Hedegaard, and Wilson Compton. 2019. "Data quality considerations when using county-level opioid overdose death rates to inform policy and practice." Drug and Alcohol Dependence 204:107549.

Jones, Jermaine, Shanthi Mogali, and Sandra Comer. 2012. "Polydrug abuse: a review of opioid and benzodiazepine combination use.” Drug and Alcohol Dependence 125 (1-2):8-18.

Kim, Bokyung. 2021. "Must-access prescription drug monitoring programs and the opioid overdose epidemic: The unintended consequences." Journal of Health Economics 75:102408.

Krueger, Alan. 2017. "Where have all the workers gone? An inquiry into the decline of the US labor force participation rate." Brookings Papers on Economic Activity 2017 (2):1-88.

Martin, Bradley, Ming-Yu Fan, Mark Edlund, Andrea DeVries, Jennifer Brennan Braden, and Mark Sullivan. 2011. "Long-term chronic opioid therapy discontinuation rates from the TROUP study." Journal of General Internal Medicine 26 (12):1450-1457.

Mauri, Amanda I., Tarlise N. Townsend, and Rebecca L. Haffajee. 2020. "The Association of State Opioid Misuse Prevention Policies With Patient- and Provider-Related Outcomes: A Scoping Review." The Milbank Quarterly 98 (1):57-105.

McClellan, Chandler. 2019. "Disparities in opioid related mortality between United States counties from 2000 to 2014." Drug and Alcohol Dependence 199:151-158.

Meara, Ellen, Jill Horwitz, Wilson Powell, Lynn McClelland, Weiping Zhou, James O'Malley, and Nancy Morden. 2016. "State legal restrictions and prescription-opioid use among disabled adults." New England Journal of Medicine 375 (1):44-53. 
Meara, Ellen and Jonathan Skinner. 2015. "Losing ground at midlife in America." Proceedings of the National Academy of Sciences 112 (49):15006-15007.

Meinhofer, Angélica. 2018. "Prescription drug monitoring programs: the role of asymmetric information on drug availability and abuse.” American Journal of Health Economics 4 (4):504-526.

Mora, Frank. 1996. "Victims of the balloon effect: Drug trafficking and US policy in Brazil and the Southern Cone of Latin America.” The Journal of Social, Political, and Economic Studies 21 (2):115140.

Muhuri, Pradip, Joseph Gfroerer, and Christine Davies. 2013. "Associations of nonmedical pain reliever use and initiation of heroin use in the United States." CBHSQ Data Review 1:17.

Murphy, Kevin, Michael Grossman, and Gary Becker. 2006. "The market for illegal goods: The case of drugs." Journal of Political Economy 114:38-60.

Office of National Drug Control Policy. 2019. "FY2020 budget and performance summary." Report, Executive Office of the President of the United States.

—. 2020. "National drug control strategy." Report, Executive Office of the President of the United States.

Oliva, Elizabeth M., Thomas Bowe, Ajay Manhapra, Stefan Kertesz, Jennifer M. Hah, Patricia Henderson, Amy Robinson, Meenah Paik, Friedhelm Sandbrink, Adam J. Gordon, and et al. 2020. "Associations between stopping prescriptions for opioids, length of opioid treatment, and overdose or suicide deaths in US veterans: observational evaluation." BMJ 368:m283.

Pardo, Bryce. 2017. "Do more robust Prescription Drug Monitoring Programs reduce prescription opioid overdose?” Addiction 112 (10):1773-1783.

Reuter, Peter and Mark Kleiman. 1986. "Risks and prices: An economic analysis of drug enforcement." Crime and Justice 7:289-340.

Rose, Adam, Dana Bernson, Kenneth Kwan Ho Chui, Thomas Land, Alexander Walley, Marc LaRochelle, Bradley Stein, and Thomas Stopka. 2018. "Potentially inappropriate opioid prescribing, overdose, and mortality in Massachusetts, 2011-2015." Journal of General Internal Medicine 33 (9):1512-1519.

Rudd, Rose, Noah Aleshire, Jon Zibbell, and Matthew Gladden. 2016. "Increases in Drug and Opioid Overdose Deaths - United States, 2000-2014.” MMWR Recommendations and Reports 64 (50):13781382.

Ruhm, Christopher. 2016. “Taking the measure of a fatal drug epidemic.” Tech. Rep. 22504, National Bureau of Economic Research.

—. 2018. "Deaths of Despair or Drug Problems?” Tech. Rep. w24188, National Bureau of Economic Research.

- 2019. "Drivers of the fatal drug epidemic." Journal of Health Economics 64:25-42.

Sacks, Daniel W., Alex Hollingsworth, Thuy Nguyen, and Kosali Simon. 2021. "Can policy affect initiation of addictive substance use? Evidence from opioid prescribing." Journal of Health Economics 76:102397.

Santos Silva, Joao and Silvana Tenreyro. 2006. "The log of gravity." Review of Economics and Statistics 88 (4):641-658. 
2011. "Further simulation evidence on the performance of the Poisson pseudo-maximum likelihood estimator." Economics Letters 112 (2):220-222.

Sant'Anna, Pedro and Jun Zhao. 2020. "Doubly robust difference-in-differences estimators." Journal of Econometrics 219 (1):101-122.

Schnell, Molly. 2017. "Physician behavior in the presence of a secondary market: The case of prescription opioids." Mimeo, Princeton University.

Schnell, Molly and Janet Currie. 2018. "Addressing the opioid epidemic: is there a role for physician education?" American Journal of Health Economics 4 (3):383-410.

Schuler, Megan, Sara Heins, Rosanna Smart, Beth Ann Griffin, David Powell, Elizabeth Stuart, Bryce Pardo, Sierra Smucker, Stephen Patrick, Rosalie Liccardo Pacula, and Bradley Stein. 2020. "The State of the science in opioid policy research.” Drug and Alcohol Dependence 214:108137.

Simoni-Wastila, Linda and Jingjing Qian. 2012. "Influence of prescription monitoring programs on analgesic utilization by an insured retiree population." Pharmacoepidemiology and Drug Safety 21 (12):1261-1268.

Smithson, Michael, Michael McFadden, and Sue-Ellen Mwesigye. 2005. "Impact of Federal drug law enforcement on the supply of heroin in Australia." Addiction 100 (8):1110-1120.

Strulik, Holger. 2021. "From pain patient to junkie: An economic theory of painkiller consumption and its impact on wellbeing and longevity." Journal of Health Economics 76:102432.

Sun, Eric, Anjali Dixit, Keith Humphreys, Beth Darnall, Laurence Baker, and Sean Mackey. 2017. "Association between concurrent use of prescription opioids and benzodiazepines and overdose: retrospective analysis." BMJ 356:1-7.

U.S. Department of Health \& Human Services. 2016. “The opioid epidemic - By the numbers.” Technical report, U.S. Department of Health \& Human Services.

Volkow, Nora. 2018. "Medications for opioid use disorder: bridging the gap in care." Lancet 391:285287.

Volkow, Nora, Thomas Frieden, Pamela Hyde, and Stephen Cha. 2014. "Medication-assisted therapies Tackling the opioid-overdose epidemic." New England Journal of Medicine 370 (22):2063-2066.

Volkow, Nora and Thomas McLellan. 2016. "Opioid abuse in chronic pain - Misconceptions and mitigation strategies." New England Journal of Medicine 374 (13):1253-1263.

Wooldridge, Jeffrey. 1999. "Distribution-free estimation of some nonlinear panel data models." Journal of Econometrics 90 (1):77-97.

Young, Alwyn. 2019. "Channeling fisher: Randomization tests and the statistical insignificance of seemingly significant experimental results.” The Quarterly Journal of Economics 134 (2):557-598.

Zhu, Wenjia, Michael Chernew, Tisamarie Sherry, and Nicole Maestas. 2019. "Initial opioid prescriptions among U.S. commercially insured patients, 2012-2017." New England Journal of Medicine 380 (11):1043-1052. 